\title{
The Functional Anatomy of Limbic Status Epilepticus in the Rat. II. The Effects of Focal Deactivation
}

\author{
Leonard E. White ${ }^{a}$ and Joseph L. Price \\ Department of Anatomy and Neurobiology, Washington University School of Medicine, St. Louis, Missouri 63110
}

Limbic status epilepticus was induced in awake, unrestrained rats by electrically stimulating the anterior piriform cortex or the basal amygdaloid nucleus for about $\mathbf{4 0} \mathrm{min}$. As described in the preceding article (White and Price, 1993), one of four stable forms of status may be induced. Each form is characterized on the basis of its behavioral and electroencephalographic manifestations, and its distinct patterns of ${ }^{14} \mathrm{C}$-2-deoxyglucose uptake and Fos-like immunoreactivity. This study was directed at identifying the epileptogenic foci of the two major forms of status, types II and III, by deactivating the basal amygdaloid nucleus, ventral hippocampal formation, amygdalohippocampal area, or anterior piriform cortex during these seizure states. Infusions of the local anesthetic lidocaine, the GABA agonist muscimol, or a vehicle solution alone were made into each of these structures during ongoing type II or type III status. The major finding is that deactivation of the basal amygdaloid nucleus terminated both types of status. This indicates that the basal nucleus is primarily responsible for the generation of widespread status epilepticus activity. Deactivation of the ventral hippocampal formation did not terminate the subconvulsive levels of status, but did prevent the recurrent development of sustained seizures with facial and forelimb clonus that characterize type III status. These models of status epilepticus may be particularly important for understanding seizure mechanisms that are not dependent upon the hippocampal formation. The possible clinical relevance of these findings is discussed in relation to temporal lobe epilepsy.

IKey words: seizure, temporal lobe epilepsy, amygdala, hippocampus, epileptogenic focus, deoxyglucose]

The overall goal of our studies in the rat has been to characterize the neural substrates of limbic status epilepticus, a condition defined by the persistent presence of self-sustaining epileptiform discharges. The preceding article describes the patterns of ${ }^{14} \mathrm{C}$ 2-deoxyglucose uptake and Fos-like immunoreactivity associated with distinct subconvulsive and convulsive forms of limbic status (White and Price, 1993). The most restrictive form of status, type $I$, is associated with the induction of a single epi-

Received Jan. 29, 1993; revised May 12, 1993; accepted May 20, 1993.

We thank Mrs. Van Tuyet Nguyen and Mr. Hieu Van Luu for their excellent technical support, and Mr. Mike Morgan for his photographic assistance. This work was funded by USPHS Grant DC00093.

Correspondence should be addressed to Joseph L. Price, Department of Anatomy and Neurobiology, Box 8108, Washington University School of Medicine, 660 South Euclid Avenue, St. Louis, MO 63110.

${ }^{3}$ Present address: Department of Neurobiology, Box 3209, Duke University Medical Center, Durham, NC 27710.

Copyright (C) 1993 Society for Neuroscience $0270-6474 / 93 / 134810-21 \$ 05.00 / 0$ leptogenic focus within a small part of the posterior-medial amygdaloid complex, called the amygdalohippocampal area. The more expansive types II and III are associated with the additional involvement of the basal nucleus of the amygdala and other structures that are connected to it. Because multiple structures were involved throughout the ventral forebrain, a single focus of these more widespread seizure states could not be identified on the basis of patterns of activity alone, and it is possible that several foci are responsible for their generation and expression. Indeed, previous studies in the rat have suggested that the amygdaloid complex, the ventral hippocampal formation, and a restricted region in the depths of the anterior piriform cortex, the so-called "area tempestas," are all critically involved in the initiation or generalization of seizure activity within the limbic forebrain (Gale and Browning, 1986; Gale, 1988; Handforth and Ackermann, 1988; Lothman et al., 1989, 1991; McIntyre et al., 1991; VanLandingham and Lothman, $1991 \mathrm{a}, \mathrm{b})$.

The present study was directed at understanding the roles of the basal amygdaloid nucleus, ventral hippocampal formation, amygdalohippocampal area, and anterior piriform cortex in type II and type III status. The experimental approach was to deactivate these structures selectively during ongoing status activity by the focal application of either lidocaine, a local anesthetic, or muscimol, an agonist of the inhibitory neurotransmitter GABA. ${ }^{14} \mathrm{C}$-2-deoxyglucose autoradiography was used to reveal the effects of the intracerebral infusions on the patterns of activation that are normally associated with each type of status. The results indicate that the basal nucleus of the amygdala, and not the ventral hippocampal formation or the anterior piriform cortex, is the primary focus of type II and type III status cpilepticus.

\section{Materials and Methods}

Surgery. The surgical procedures for these studies were the same as those described in the preceding article (White and Price, 1993). Briefly, adult Sprague-Dawley rats were anesthetized with sodium pentobarbital $(60 \mathrm{mg} / \mathrm{kg}$, i.p.) or halothane $(0.25-0.50 \%)$ in a $2: 1$ mixture of nitrous oxide and oxygen, and prepared for surgery. A catheter was implanted into the left femoral vein for the infusion of a ${ }^{14} \mathrm{C}-2$-dcoxyglucosc solution, and a concentric bipolar electrode was implanted into the basal nucleus of the amygdala or the anterior piriform cortex for electrical stimulation and depth electroencephalographic (EEG) recording. In addition, a 20 or 22 gauge guide cannula (Plastics One) was implanted into the brain for infusions into one of four sites within the ventral forebrain: the anterior piriform cortex $\left(\mathrm{AP}+2.7, \mathrm{ML}+2.8, \mathrm{DV}_{\text {dura }}\right.$ $-6.5)$, the basal nucleus of the amygdala $\left(\mathrm{AP}-2.8, \mathrm{ML}+4.7, \mathrm{DV}_{\text {dura }}\right.$ -7.7), the amygdalohippocampal area (AP - 3.8, ML +3.7, $\mathrm{DV}_{\text {dura }}$ -8.3 ), or the ventral hippocampal formation ( $\mathrm{AP}-5.3, \mathrm{ML}+4.8$, $\mathrm{DV}_{\text {dura }}-7.0$ ) (stereotaxic coordinates from Paxinos and Watson, 1986). 
These guide cannulas were used to direct the needle of a microsyringe or an inner cannula to the targeted structure (see Fig. $1 A$ ). In order to avoid injury to the targeted structure prior to the insertion of the needle or inner cannula, the tip of guide cannula was implanted about $4 \mathrm{~mm}$ above the target. When the guide cannula was positioned for infusions into the anterior piriform cortex, the concentric bipolar electrode was implanted into the basal nucleus of the amygdala; in all other surgical preparations, the electrode was placed in the anterior piriform cortex. Anchoring screws were inserted into the skull, and leads from the electrode and skull screws were secured in a plastic pedestal for subsequent attachment to a multichannel cable. The entire assembly was attached to the skull with acrylic cement, and the animal was allowed to recover for 5-10 d.

Limbic status epilepticus experiment. The anterior piriform cortex or the basal amygdaloid nucleus was electrically stimulated continuously for 30-60 min to induce limbic status epilepticus, as described in the preceding article (White and Price, 1993). The experiments described here investigated status types II and III only, because these types were induced in $91 \%$ of all the rats that developed status epilepticus.

After about $30 \mathrm{~min}$ of type II or type III status, the drug or vehicle solution was infused by one of two methods. In the initial experiments, the rat was manually restrained, a $1 \mu \mathrm{l}$ Hamilton syringe (Fisher) was inserted through the 20 gauge guide cannula and $50-200 \mathrm{nl}$ of solution was injected. The restraint was continued and the syringe was held in place for an additional $60 \mathrm{sec}$ to promote the local diffusion of the injectate. This method was abandoned because a few rats experienced respiratory distress during or just after the restraint.

In most experiments, a $1 \mu \mathrm{l}$ Hamilton syringe was filled with distilled water and inserted into a $30 \mathrm{~cm}$ length of polyethylene cannula tubing (Plastics One, Single Cannula System), which was filled with the vehicle or drug solution. The other end of the tubing was fitted with a 26 gauge inner cannula, so that depressing the plunger of the syringe extruded a graduated volume of solution from the cannula. The entire cannula apparatus was secured to the multichannel electrode cable and suspended above the cage at the beginning of the experiment. The inner cannula was partially inserted into the guide cannula and secured at this position with tape, taking care to avoid protrusion of the inner cannula beyond the tip of the guide cannula and into the brain. After about 30 min of type II or type III status, the inner cannula was pushed down fully into the guide cannula, with minimal hindrance to the mobility of the animal. The EEG and behavioral patterns were carefully observed for another 10-20 min for possible effects of cannula insertion per se on the seizure state, and then a total of $100-1000 \mathrm{nl}$ of the vehicle or drug solution was infused. The vehicle solution consisted of $0.25 \%$ horseradish peroxidase (HRP) (type VI-A, Sigma) in normal saline buffered in $0.1 \mathrm{~m}$ sodium phosphate (pH 7.3). The drug solution was either $2 \mathrm{~m}$ lidocaine or 40-500 mM muscimol in the same vehicle. Typically, $100 \mathrm{nl}$ of the drug solution was infused initially. If no clinical effects resulted, an additional $100 \mathrm{nl}$ was infused every minute until a total volume of about $1 \mu \mathrm{l}$ was reached. In control experiments, infusions of the vehicle solution alone were performed to match the drug infusions in volume and rate of delivery.

About $30 \mathrm{~min}$ after the intracerebral infusion, a warmed solution $\left(37^{\circ} \mathrm{C}\right.$ ) of $1{ }^{14} \mathrm{C}-2$-deoxyglucose (American Radiolabeled Chemicals; specific activity, $55 \mathrm{mCi} / \mathrm{mmol} ; 60 \mu \mathrm{Ci} / \mathrm{kg}$ ) was administered intravenously (Fig. $1 B$ ). Forty-five minutes later, the rat was deeply anesthetized with sodium pentobarbital and perfused transcardially with $0.1 \mathrm{M}$ sodium phosphate buffer $(\mathrm{pH} \mathrm{7.3)}$ and $4 \%$ paraformaldehyde buffered in $0.1 \mathrm{~m}$ sodium phosphate $(\mathrm{pH} 7.3)$. The brain was removed, frozen, sectioned, and processed for ${ }^{14} \mathrm{C}$-2-deoxyglucose autoradiography, as described previously (White and Price, 1993). In addition, an adjacent set of sections near the site of infusion was collected. These sections were melted onto subbed coverslips and processed for peroxidase histochemistry using tetramethylbenzidine as the chromogen (Mesulam, 1978).

Data analysis. For each experiment, the EEG was analyzed quantitatively to evaluate the effects of the intracerebral infusions on the clinical manifestations of status epilepticus. Two kinds of EEG features were considered. First, the mean frequency of the periodic epileptiform discharges, which characterize type II status and the "interictal" phases of type III status, was determined for each 5 min interval from $30 \mathrm{~min}$ before the infusion to at least $50 \mathrm{~min}$ after the infusion. Second, for animals in type III status, the time spent in overt seizure activity before and after the intracerebral infusion was assessed by measuring the total duration of the discrete segments of high-frequency discharges for the

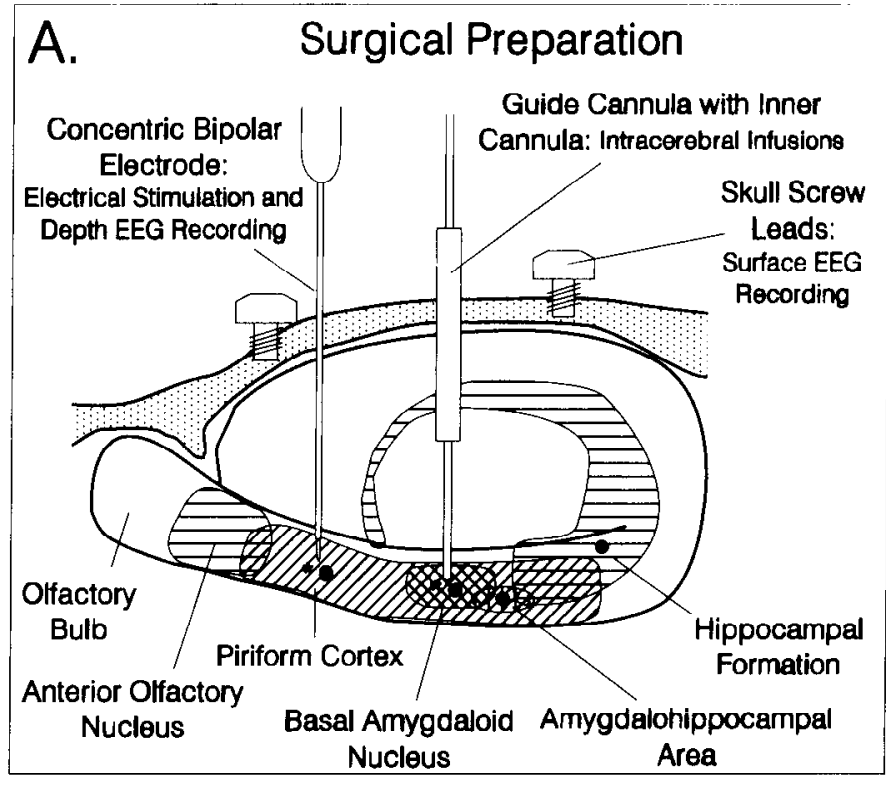

B.

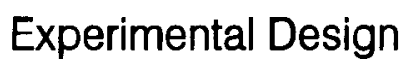

Intracerebral Lidocaine or Vehicle Solution (0.25\% HRP/normal saline)

Intravenous [14C]2-Deoxyglucose

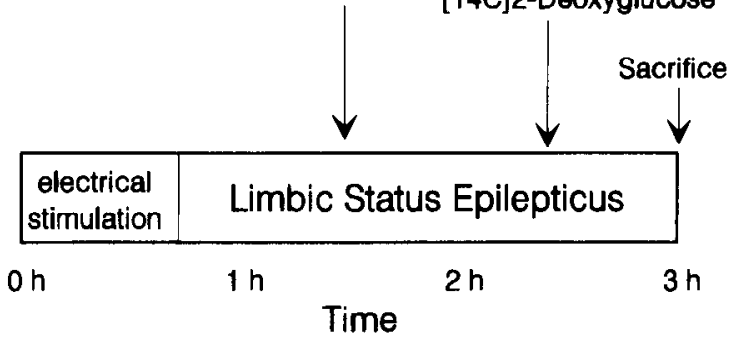

Figure 1. Schematic depiction of the surgical preparation $(A)$ and experimental design $(B)$. $A$, A concentric bipolar electrode implanted into the anterior piriform cortex or the basal amygdaloid nucleus was used for electrical stimulation and subsequent depth EFG recording (marked by ${ }^{*}$ ). Either structure, the amygdalohippocampal area, or the ventral hippocampal formation was targeted for an intracerebral infusion (marked by $)$. $B$, In each rat, limbic status epilepticus was induced by applying 30-60 min of electrical stimulation. After about $45 \mathrm{~min}$ of status, a drug or vehicle solution was infused into one of the four sites, and about 30 min later, a solution of ${ }^{14} \mathrm{C}$-2-deoxyglucose was administered intravenously.

30 min intervals immediately before and after the infusion. The data for animals within a group that received the same kind of intracerebral infusion were pooled, and the differences between corresponding means from lidocaine and vehicle infusion groups were tested for statistical significance using a Student's $t$ test.

The ${ }^{14} \mathrm{C}$-2-deoxyglucose autoradiograms were examined in a systematic, qualitative manner in each case. The contrast of the autoradiographic images was enhanced using a computer-based image processor (Drexel University BRAIN Autoradiographic Analysis Software Package) for analysis and photographic presentation.

The area of diffusion of the horseradish peroxidase reaction product was mapped in each case with the use of both bright-field and darkfield microscopy. The area that contained peroxidase reaction product, as viewed under dark-field illumination, was taken as a conservative approximation of the diffusion of the drug or vehicle solution. Since lidocaine is presumably more lipophilic than horseradish peroxidase, the actual volume of lidocaine diffusion may have exceeded that of HRP. 

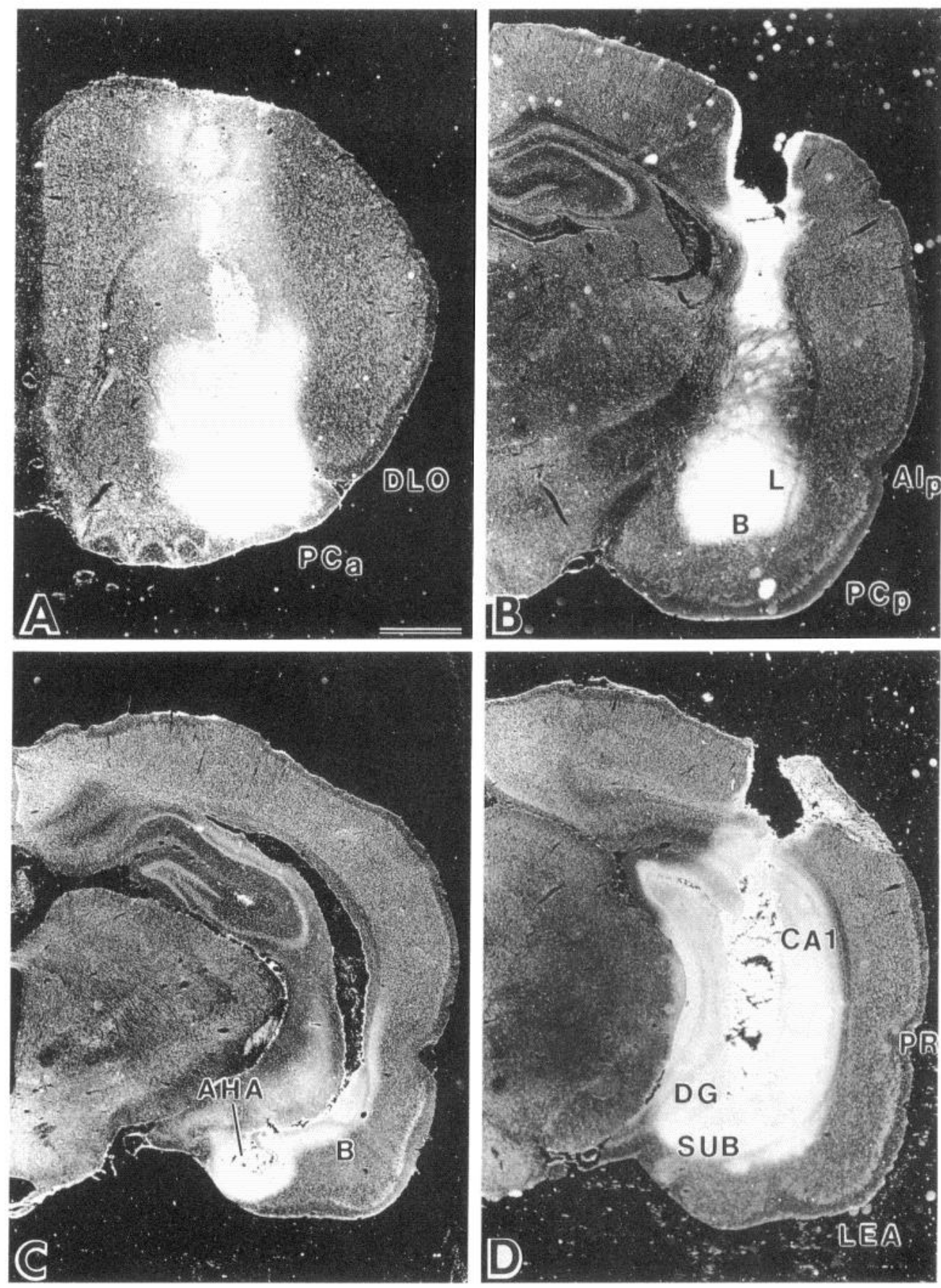

Figure 2. Dark-field photomicrographs of the distribution of HRP reaction product after intracerebral infusions into the anterior subdivision of the piriform cortex $(A)$, the basal nucleus of the amygdala $(B)$, the amygdalohippocampal area $(C)$, and the ventral hippocampal formation $(D)$. For abbreviations, see Appendix. Scale bar, $1 \mathrm{~mm}$.

\section{Results}

Infusions during type II status

\section{Infusions into the basal nucleus of the amygdala}

Extent of the infusions. In these experiments, infusions of either the drug solution or the vehicle alone were placed into the basal amygdaloid nucleus during type II status. A portion of the basal and lateral amygdaloid nuclei was directly lesioned by the injection cannula in each case and, as judged by the diffusion of peroxidase reaction product, the solutions spread throughout the middle two-thirds of the basal and lateral nuclei (Fig. $2 B$ ). In addition, reaction product was variably found in adjacent amygdaloid regions, particularly in the central and accessory basal nuclei, and there was some HRP reaction product along the cannula track in the overlying caudate-putamen and somatosensory cortex.

Effects of the infusions. Four successful experiments were obtained in which type II status was induced by electrical stimulation of the anterior piriform cortex and 400-1000 nmol of lidocaine were infused into the deep amygdaloid nuclei (Table 1). The result was a striking and sudden attenuation of the clinical manifestations of type II status. The incessant exploratory activities that characterize this level of status ceased. Thereafter, most of the rats remained still, in a resting posture, and some appeared to fall asleep. This profound change in the behavioral manifestations of type II status coincided with a rapid decomposition of the regular pattern of epileptiform discharges (Figs. 3A, 4). Before the infusions, large-amplitude (200- 
$400 \mu \mathrm{V})$ EEG discharges occurred at a frequency of about $1 \mathrm{~Hz}$. After the infusion of lidocaine and throughout the remainder of the experiment, only sporadic discharges were recorded from the depth electrode, at a rate of about one every $20-30 \mathrm{sec}$; these behavioral and EEG patterns closely resembled those seen in type I status (White and Price, 1993). Typically, these changes were evident within $2 \mathrm{~min}$ after the infusion.

The patterns of ${ }^{14} \mathrm{C}$-2-deoxyglucose uptake in these four cases indicated that the infusion of lidocaine deactivated the basal amygdaloid nucleus and most of the other elements of the anatomical substrate associated with type II status (Fig. 5). After the infusion, the only structures that continued to display elevated ${ }^{14} \mathrm{C}$-2-deoxyglucose uptake were the amygdalohippocampal area (Fig. $5 F$ ) and, to a lesser degree, a caudal portion of the bed nucleus of the stria terminalis (Fig. 5D). The levels of ${ }^{14} \mathrm{C}$-2-deoxyglucose uptake in all other regions of the forebrain, including the deep amygdaloid nuclei, were similar to those found in the resting state. This restricted pattern of activation and the associated clinical manifestations are identical to those seen in type I status (cf. Fig. 4 of White and Price, 1993). Thus, the infusion of lidocaine into the basal amygdaloid nucleus resulted in a conversion of type II status to type I.

Infusions of the vehicle solution alone into the basal amygdaloid nucleus had no effect on the clinical manifestations of type II status in each of five control experiments (Table 1). The behavioral and EEG patterns that characterize type II status continued after the infusion (Fig. 4), and the overall pattern of ${ }^{14} \mathrm{C}$-2-deoxyglucose uptake was similar to the usual pattern associated with type II status (Fig. 5). Only restricted regions along the cannula track that were directly lesioned by the inner cannula appeared to be hypometabolic. More rostral and caudal parts of the basal amygdaloid nucleus accumulated large amounts of ${ }^{14} \mathrm{C}$-2-deoxyglucose. Thus, the direct focal lesion and the infusion of the vehicle solution alone were not sufficient to deactivate the full extent of the basal nucleus, or to attenuate the clinical manifestations of type II status.

In four experiments, 4-200 $\mathrm{nmol}$ of muscimol was used in attempts to deactivate the basal amygdaloid nucleus (Table 1). These amounts of muscimol are far greater than those used in previous studies to suppress neuronal activity within local brain regions in unanesthetized animals, and to produce significant changes in ${ }^{14} \mathrm{C}$-2-deoxyglucose uptake (e.g., Gale, 1985; Morimoto et al., 1986; Martin, 1991). In three of the four cases, the infusion of muscimol failed to produce any effects on the behavioral or EEG manifestations of type II status. The associated pattern of ${ }^{14} \mathrm{C}$-2-deoxyglucose uptake was similar to the pattern following the infusion of the vehicle solution alone. In the fourth case, the infusion of $4 \mathrm{nmol}$ of muscimol completely attenuated the type II status, in an identical fashion to that described above for the infusion of lidocaine. In this case, the basal nucleus and all other structures that are specifically involved in type II status were deactivated, but the level of activity within the amygdalohippocampal area was unchanged. Therefore, large concentrations of muscimol were inconsistent in deactivating the basal nucleus, but when the basal nucleus was deactivated, type II status ceased.

Infusions during type III status epilepticus

Infusions into the basal nucleus of the amygdala

Extent of the infusions. The track of the inner cannula and the spread of peroxidase reaction product were the same for this
Table 1. Intracerebral infusions of vehicle and drug solutions into the basal nucleus of the amygdala during type II status

\begin{tabular}{|c|c|c|c|}
\hline Solution $^{a}$ & $\begin{array}{l}\text { Number } \\
\text { of } \\
\text { animals }\end{array}$ & $\begin{array}{l}\text { Clinical } \\
\text { result }\end{array}$ & $\begin{array}{l}{ }^{14} \mathrm{C}-2- \\
\text { Deoxyglucose } \\
\text { pattern }\end{array}$ \\
\hline Vehicle & $5 / 5$ & No effect & Type Il status \\
\hline $\begin{array}{c}400-1000 \mathrm{nmol} \\
\text { of lidocaine }\end{array}$ & $4 / 4$ & $\begin{array}{l}\text { Attenuation of } \\
\text { type II status; } \\
\text { thereafter, } \\
\text { only sporadic } \\
\text { epileptiform } \\
\text { discharges }\end{array}$ & Type I status \\
\hline $4-200 \mathrm{nmol}$ & $3 / 4$ & No effect & Type II status \\
\hline
\end{tabular}

of muscimol

1/4 Attenuation of Type I status
type II status;
thereafter,
only sporadic
epileptiform
discharges

"The vehicle for all infusions was $0.25 \% \mathrm{HRP}$ in $0.9 \%$ saline, buffered in $0.1 \mathrm{M}$ sodium phosphate.

"Refer to Figures 4 and 6 of White and Price (1993) for the patterns of ${ }^{14} \mathrm{C}-2$ deoxyglucose uptake associated with type I and type II status, respectively, from animals without implanted guide cannulas and intracerebral infusions.

- The type II status pattern was seen in all but one animal; in the other rat, the intravenous infusion of the ${ }^{14} \mathrm{C}$-2-deoxyglucose solution induced a sudden attenuation of type II status, and a conversion to type I status.

set of experiments as for the amygdaloid infusions during type II status, described above.

Effects of the infusions. The infusion of lidocaine into the basal amygdaloid nucleus during type III status produced "allor-none" results, in an apparent dose-dependent fashion. Onc of two clinical outcomes was observed. Either there was no effect on the behavioral and EEG manifestations of type III status, or type III status was suddenly aborted. In every experiment, the activation of the basal nucleus was strictly related to the expression of type III status. In cases in which the infusion of lidocaine failed to deactivate the basal nucleus, type III status continucd. Conversely, in those cases in which the basal nucleus was successfully deactivated with lidocaine, type III status ceased.

Thus, in one case that received an infusion of $14 \mathrm{nmol}$ of lidocaine, and in all that received $200 \mathrm{nmol}$ or more of lidocaine, the infusions produced a cessation of type III status (Table 2). This frank behavioral change coincided with the rapid decay of the characteristic pattern of "interictal" epileptiform discharges and discrete segments of high-frequency spiking (Figs. $3 B, 6$ ). Thereafter, sporadic discharges were observed at a variable rate of about one every $10-30 \mathrm{sec}$. This effect was entirely analogous to the results of infusions of comparable amounts of lidocaine in to the basal amygdaloid nucleus during type II status. It should be borne in mind that these results were obtained in rats in which either type II or type III status was induced by electrical stimulation of the anterior piriform cortex.

The pattern of ${ }^{14} \mathrm{C}$-2-deoxyglucose uptake indicated that the infusion of lidocaine deactivated not only the basal nucleus, but also all of the other anatomical elements specifically associated with type III status, including the site of electrical stimulation (i.e., the anterior piriform cortex). In five of these rats, only the amygdalohippocampal area (Fig. $7 F$ ) and the caudal portions 
A Basal Amygdaloid Nucleus injection
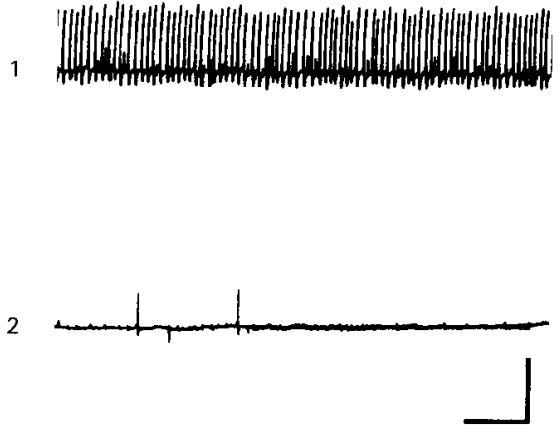

C Ventral Hippocampal Formation Injection
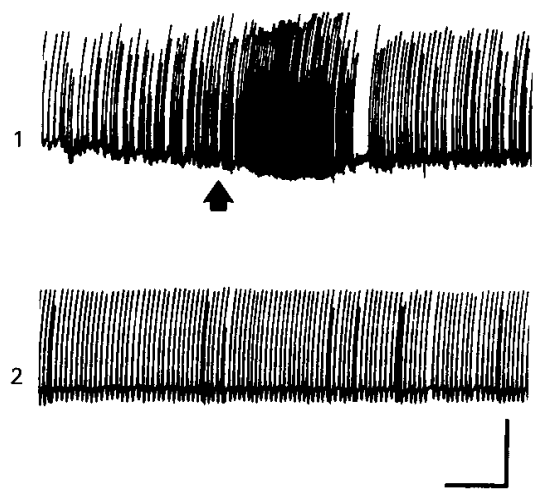

B Type III Status Basal Amygdaloid Nucleus Injection

1
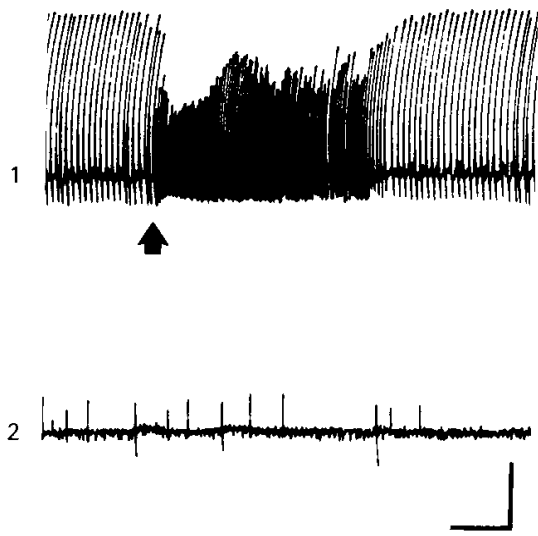

Type III Status

Amygdalohippocampal Area Injection

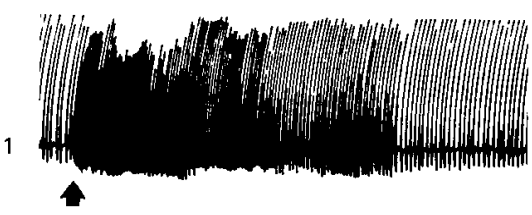

2

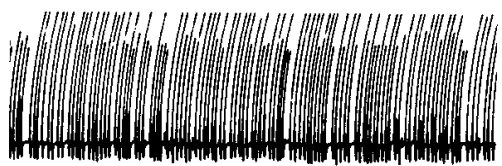

3

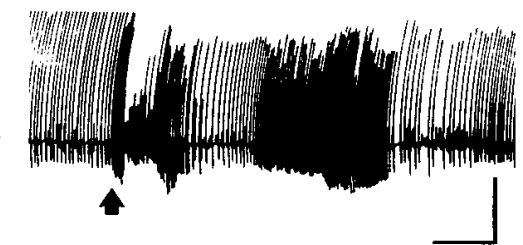

Figure 3. Effects of infusing lidocaine into forebrain structures during type II or type III status epilepticus. For each record, the EEG activity was recorded with a concentric bipolar electrode implanted into the anterior piriform cortex, and arrows mark the onset of sustained ictal discharges and seizures with facial and forelimb clonus. $A$, Infusion of $400 \mathrm{nmol}$ of lidocaine in $200 \mathrm{nl}$ of solution into the basal nucleus of the amygdala during type II status. The upper trace $(A I)$ was recorded $10 \mathrm{~min}$ before the infusion, and the lower trace $(A 2)$ was taken $35 \mathrm{~min}$ after the infusion. This infusion produced a marked attenuation of the clinical manifestations of type II status. $B$, Infusion of $800 \mathrm{nmol}$ of lidocaine in $200 \mathrm{nl}$ of solution into the basal nucleus of the amygdala during type III status. The upper trace $(B I)$ was recorded 5 min before the infusion, and the lower trace $(B 2)$ was taken $55 \mathrm{~min}$ after the infusion. As in type II status, deactivation of the basal nucleus with lidocaine attenuated type III status. $C$, Infusion of $200 \mathrm{nmol}$ of lidocaine in $100 \mathrm{nl}$ of solution into the ventral hippocampal formation during type III status. The records were taken 25 min before the infusion $(C l)$ and 30 min after the infusion $(C 2)$. This infusion selectively suppressed the development of sustained high-frequency spiking and facial and forelimb clonus seizures, without producing major changes in the pattern of the "interictal" discharges. $D$, Infusion of 800 nmol of lidocaine in $400 \mathrm{nl}$ of solution into the amygdalohippocampal area during type III status. The records were taken 10 min before the infusion $(D I)$, and 5 and 50 min after the infusion (D2 and $D 3$, respectively). The infusion resulted in the transient suppression of sustained high-frequency spiking and seizures with facial and forelimb clonus, without producing major changes in the pattern of the "interictal" discharges. In this case, the ictal episodes were suppressed for $22 \mathrm{~min}$. Horizontal calibration, $10 \mathrm{sec}$; vertical calibration: $50 \mu \mathrm{V}$ in $B, 100 \mu \mathrm{V}$ in $A$, and $200 \mu \mathrm{V}$ in $C$ and $D$.

of the bed nucleus of the stria terminalis (Fig. $7 D$ ) maintained elevated levels of ${ }^{14} \mathrm{C}$-2-deoxyglucose uptake. In three other experiments, some residual activity remained in the extreme caudal pole of the basal amygdaloid nucleus, as well as the amygdalohippocampal area (not illustrated). Overall, the result of the infusion of large amounts of lidocaine into the basal nucleus during type III status was the same as during type II status.
Both clinical and autoradiographic patterns were converted into those normally associated with type I status.

In most of these experiments, the animals were killed about 90 min after the infusion of lidocaine. The effects of these infusions remained throughout the duration of the experiment, and the clinical manifestations of type III status (or type II status) did not return. Indeed, in one case, the rat was allowed 


\section{Infusions into the Basal Amygdaloid Nucleus during Type II Status}

A.

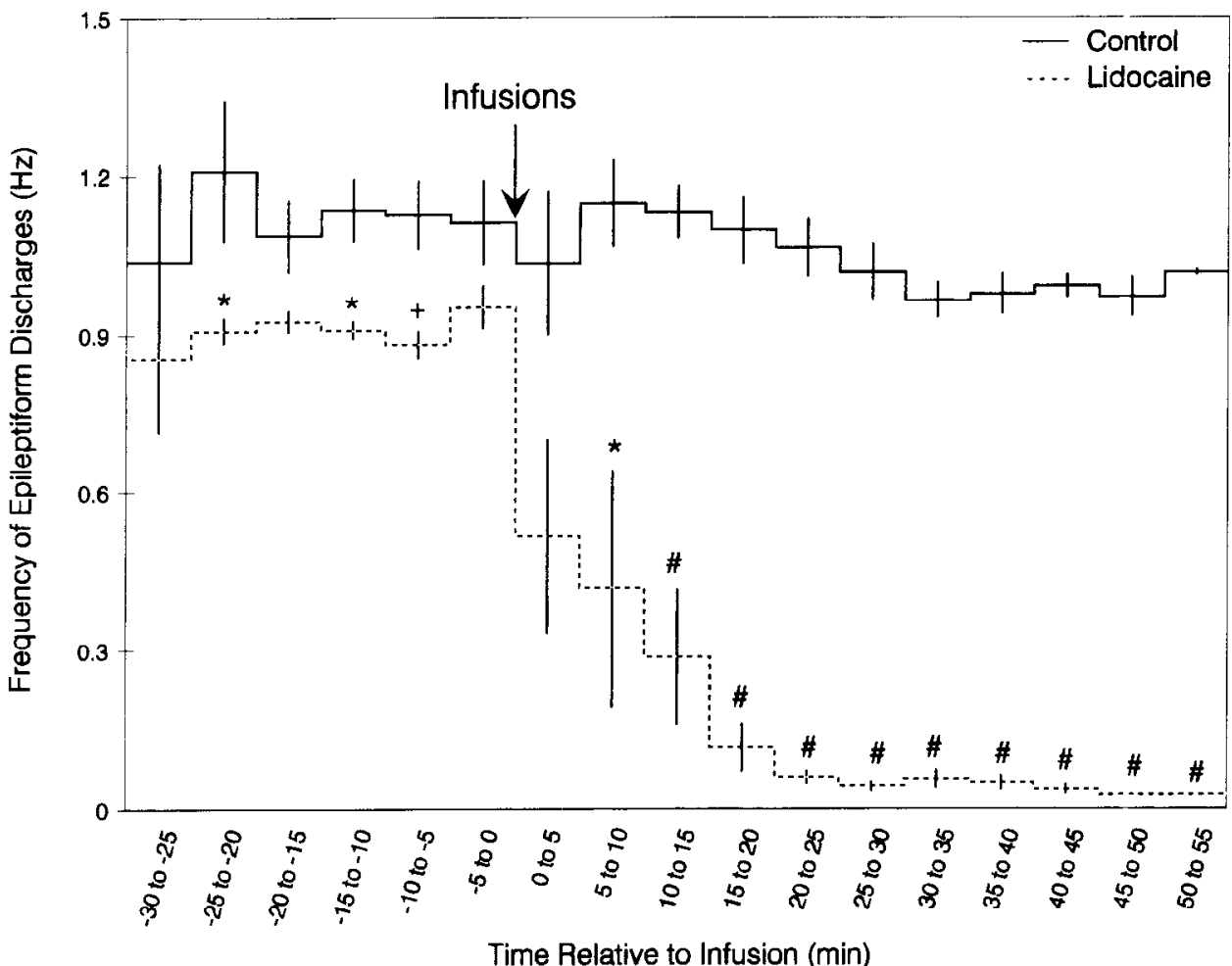

B.

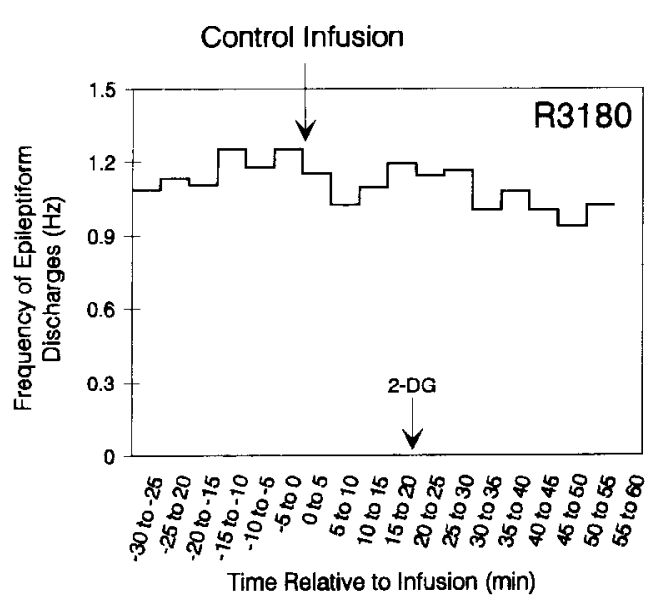

Group Summary

Representataive Cases

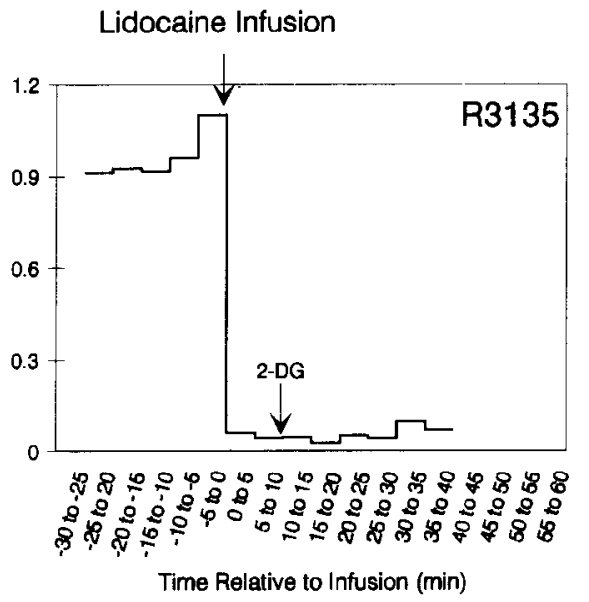

Figure 4. Analysis of EEG records from experiments in which the vehicle alone (Control, $n=5$ ) or lidocaine ( $n$ $=4$ ) was infused into the basal nucleus of the amygdala during type II status. $A$, Summary of the results from all cases. For each experiment, the mean epileptiform discharge frequency was determined for 5 min segments of the EEG record, from $30 \mathrm{~min}$ before the infusion to $55 \mathrm{~min}$ after. The values for each time segment were averaged within treatment groups; vertical lines represent SEM. The symbols identify significant differences between corresponding values: ${ }^{*}, p<0.05 ;+, p<0.01 ; \#$, $p<0.001$. $B$, Analysis of EEG patterns from individual representative cases with infusion of the vehicle alone (left) or lidocaine (right). In each experiment, the ${ }^{14} \mathrm{C}$-2-deoxyglucose solution (2-DG) was administered intravenously after the intracerebral infusion. to survive for about $14 \mathrm{hr}$ after the lidocaine treatment and there were no indications of type II or type III status. Since lidocaine infused intracerebrally is rapidly cleared from the tissue (Martin, 1991), the effects of the lidocaine infusions on type III status presumably outlasted the presence of the drug within the amygdala.

In marked contrast to these profound effects of large doses of lidocaine, infusions of less than $200 \mathrm{nmol}$ of lidocaine did not alter the behavioral or EEG patterns of type III status in five of six cases (Table 2). The patterns of ${ }^{14} \mathrm{C}$-2-deoxyglucose uptake in these five cases were identical to the patterns associated with the infusion of the vehicle solution alone. There were no indi- cations that these low concentrations of lidocaine affected the patterns of ${ }^{14} \mathrm{C}$-2-deoxyglucose uptake within the basal amygdaloid nucleus or elsewhere in the forebrain.

Infusions of the vehicle solution alone into the basal nucleus had no major effects on the clinical manifestations of type III status. The behavioral and EEG patterns continued with no significant changes (Fig. 6, Table 2), although some rats experienced fewer episodes of facial and forelimb clonus following the vehicle infusion. Nonetheless, the associated pattern of ${ }^{14} \mathrm{C}$ 2-deoxyglucose uptake in each animal corresponded to the typical pattern seen with type III status, with the exception of a restricted volume of tissue that was directly lesioned by the inner 

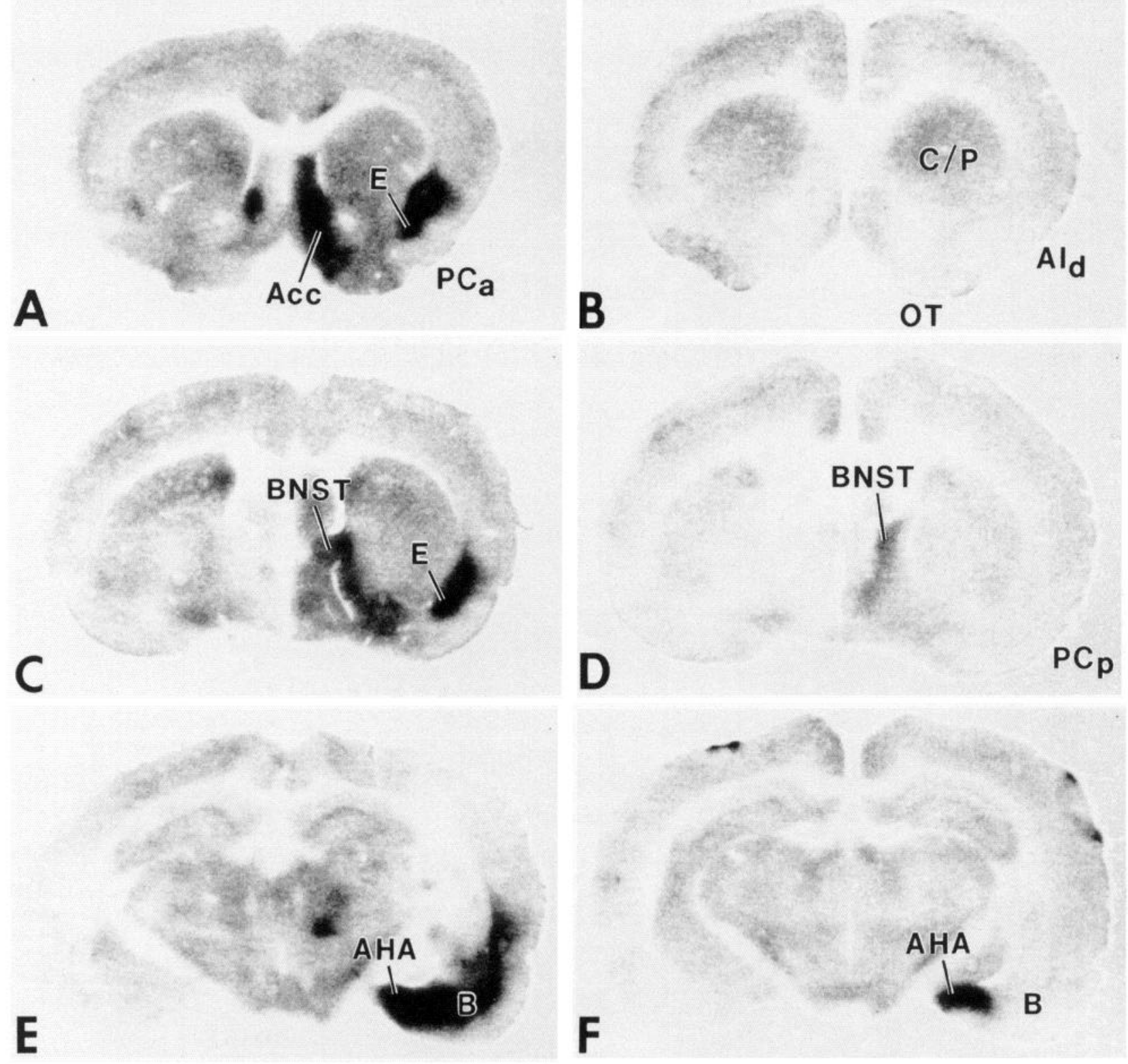

E
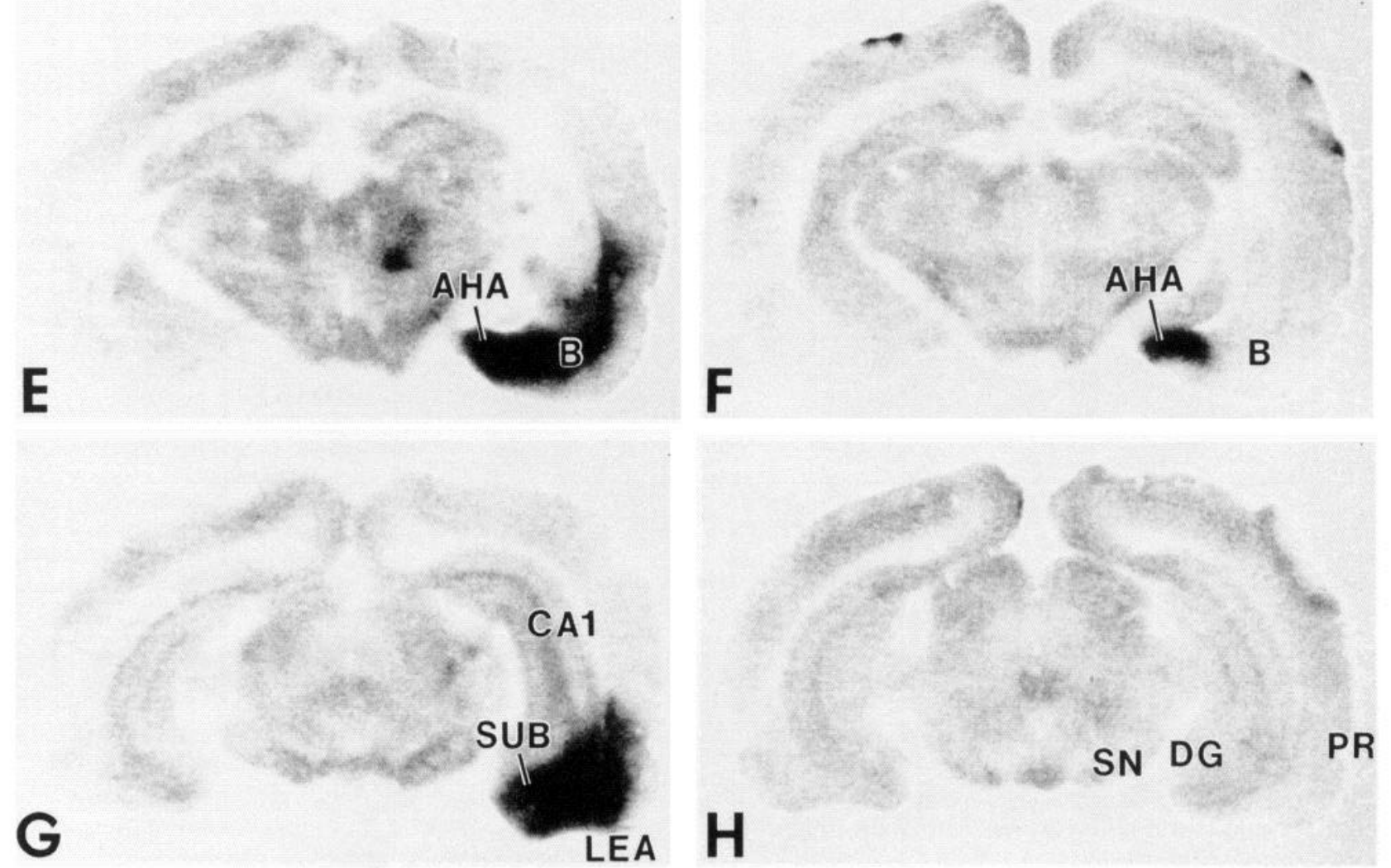

Figure 5. Patterns of ${ }^{14} \mathrm{C}$-2-deoxyglucose uptake after an infusion of $600 \mathrm{nl}$ of the vehicle alone (left column) or $400 \mathrm{nmol}$ of lidocaine in $200 \mathrm{nl}$ of solution (right column) into the basal nucleus of the amygdala during type II status. The vehicle infusion had little effect on the clinical manifestations of type II status, or on the typical pattern of ${ }^{14} \mathrm{C}$-2-deoxyglucose uptake $(A, C, E, G)$. In contrast, the infusion of lidocaine deactivated the basal nucleus $(F)$ and all other anatomical structures that are specifically associated with type II status. Only the amygdalohippocampal area $(F)$ and, to a lesser degree, a posterior portion of the bed nucleus of the stria terminalis $(D)$ remained active. This residual pattern of activation is identical to that seen in type I status. For abbreviations, see Appendix. 
Table 2. The intracerebral infusions of vehicle and drug solutions into the anterior subdivision of the piriform cortex, the basal nucleus of the amygdala, the amygdalohippocampal area, or the ventral hippocampal formation during type III status

\begin{tabular}{|c|c|c|c|c|}
\hline Infusion site & Solution $^{a}$ & $\begin{array}{l}\text { Number } \\
\text { of } \\
\text { animals }\end{array}$ & Clinical result & $\begin{array}{l}{ }^{14} \mathrm{C} \text {-2-Deoxyglucose } \\
\text { pattern }{ }^{b}\end{array}$ \\
\hline \multirow{2}{*}{$\begin{array}{l}\text { Anterior piriform } \\
\text { cortex }\end{array}$} & Vehicle & $3 / 3$ & No effect & Type III status \\
\hline & $\begin{array}{l}50 \mathrm{nmol} \text { of } \\
\text { muscimol or } \\
1000 \mathrm{nmol} \\
\text { of lidocaine }\end{array}$ & $2 / 2$ & No effect & $\begin{array}{l}\text { Type III status with local } \\
\text { deactivation of dorsal } \\
\text { endopiriform nucleus, } \\
\text { piriform cortex, and } \\
\text { agranular insular cortex }\end{array}$ \\
\hline \multirow{5}{*}{$\begin{array}{l}\text { Basal amygdaloid } \\
\text { nucleus }\end{array}$} & Vehicle & $6 / 6$ & No effect & Type III status \\
\hline & $\begin{array}{l}\text { 4-200 nmol of } \\
\text { lidocaine }\end{array}$ & $5 / 6$ & No effect & Type III status \\
\hline & & $1 / 6$ & $\begin{array}{l}\text { Attenuation of type III } \\
\text { status; thereafter, only } \\
\text { sporadic epileptiform } \\
\text { discharges }\end{array}$ & Type I status \\
\hline & $\begin{array}{c}200-1200 \mathrm{nmol} \\
\text { of lidocaine }\end{array}$ & $7 / 7$ & $\begin{array}{l}\text { Attenuation of type III } \\
\text { status; thereafter, only } \\
\text { sporadic epileptiform } \\
\text { discharges }\end{array}$ & Type I status ${ }^{d}$ \\
\hline & $\begin{array}{c}\text { 4-50 nmol of } \\
\text { muscimol }\end{array}$ & $8 / 8$ & No effect & Type III status \\
\hline \multirow{3}{*}{$\begin{array}{l}\text { Amygdalohippo- } \\
\text { campal area }\end{array}$} & Vehicle & $3 / 3$ & No effect & Type III status \\
\hline & $\begin{array}{c}800-1000 \mathrm{nmol} \\
\text { of lidocaine }\end{array}$ & $1 / 6$ & No effect & Type III status \\
\hline & & $5 / 6$ & $\begin{array}{l}\text { Transient suppression of } \\
\text { facial and forelimb } \\
\text { clonus seizures }\end{array}$ & $\begin{array}{l}\text { Type III status with local } \\
\text { deactivation of most of } \\
\text { amygdalohippocampal } \\
\text { area }\end{array}$ \\
\hline \multirow{3}{*}{$\begin{array}{l}\text { Ventral } \\
\text { hippocampal } \\
\text { formation }\end{array}$} & Vehicle & $5 / 5$ & No effect & Type III status \\
\hline & $\begin{array}{c}200-1200 \mathrm{nmol} \\
\text { of lidocaine }\end{array}$ & $1 / 6$ & No cffect & $\begin{array}{l}\text { Type III status with partial } \\
\text { deactivation of ventral } \\
\text { hippocampal formation }\end{array}$ \\
\hline & & $5 / 6$ & $\begin{array}{l}\text { Long-lasting suppression } \\
\text { of facial and forelimb } \\
\text { clonus seizures }\end{array}$ & Type II status \\
\hline
\end{tabular}

\footnotetext{
${ }^{a}$ All vehicle solutions contained $0.9 \%$ saline buffered in $0.1 \mathrm{~m}$ sodium phosphate, and most contained $0.25 \% \mathrm{HRP}$.

${ }^{n}$ Refer to Figures 4, 6, and 9 of White and Price (1993) for the patterns of ${ }^{14} \mathrm{C}$-2-deoxyglucose uptake associated with status types I, II, and III, respectively, from animals without implanted guide cannulas and intracerebral infusions.

"The type III status pattern was seen in all but two animals; in the other two rats, the intravenous infusion of the ${ }^{14} \mathrm{C}$ 2-deoxyglucose solution induced a sudden attenuation of type III status and a conversion to type II status in one rat, and type I status in another.

"In addition to the type I status pattern, the extreme caudal pole of the basal amygdaloid nucleus remained active in three rats.

" The type III status pattern was seen in seven animals; in the other rat, the intravenous infusion of the ${ }^{14} \mathrm{C}$-2-deoxyglucose solution induced a sudden attenuation of type III status and a conversion to type $I$ status. In five of these seven rats, the overall pattern of ${ }^{14} \mathrm{C}$-2-deoxyglucose uptake was similar to the pattern in rats that received an infusion of the vehicle solution, but the lateral amygdaloid nucleus was hypometabolic.

In most cascs, the ${ }^{14} \mathrm{C}$-2-dcoxyglucose was infused after or just before the redevelopment of recurrent seizure activity with facial and forelimb clonus.
}

cannula and was therefore hypometabolic. Despite a focal lesion near the middle of the basal amygdaloid nucleus, anterior and posterior parts of the basal nucleus remained strongly active.

In seven rats, large doses of muscimol were infused into the basal amygdaloid nucleus during type III status. In contrast to large doses of lidocaine, infusions of 4-50 $\mathrm{nmol}$ of muscimol did not deactivate the basal nucleus, and had no effects on the clinical manifestations of type III status (Table 2). The accom- 


\section{Infusions into the Basal Amygdaloid Nucleus during Type III Status}

A.

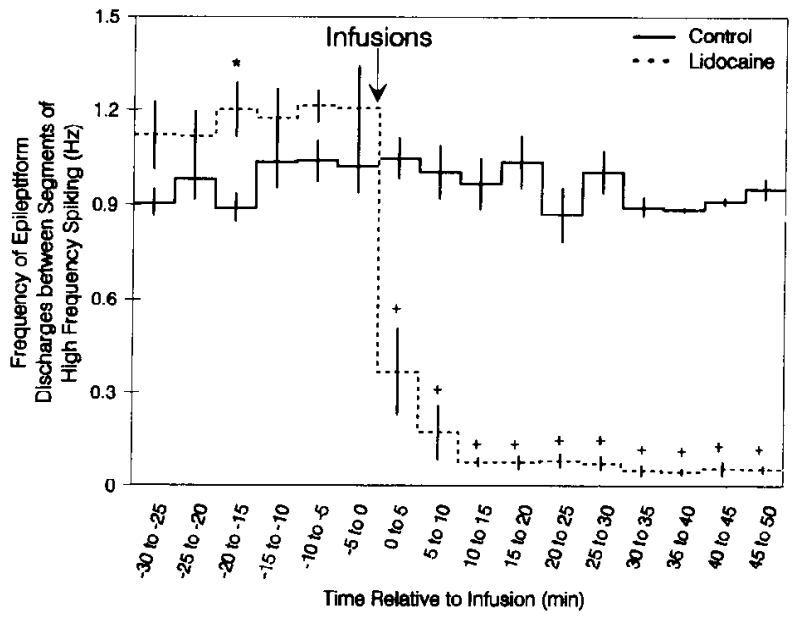

Group Summary

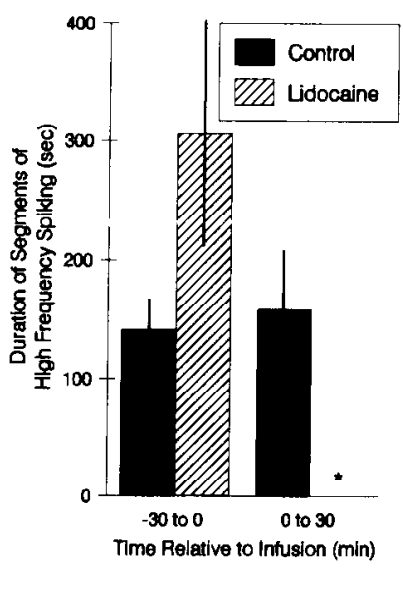

Figure 6. Analysis of EEG records from experiments in which the vehicle alone (Control, $n=6$ ) or $>200 \mathrm{nmol}$ lidocaine $(n=7)$ was infused into the basal nucleus of the amygdala during type III status. For each experiment, the mean epileptiform discharge frequency was determined for $5 \mathrm{~min}$ segments of the EEG record, from $30 \mathrm{~min}$ before the infusion to 50 or $60 \mathrm{~min}$ after (left panel of $A$, solid line in panels of $B$ ). In addition, the time spent in seizures with facial and forelimb clonus was assessed by measuring the total duration of the discrete segments of high-frequency spiking for the $30 \mathrm{~min}$ intervals immediately before and after the infusion (right panel in $A$ ), or for each $5 \mathrm{~min}$ interval throughout the experiment (broken lines in $B$ ). $A$, Summary of the results from all cases. The symbols identify significant differences between corresponding mean valucs: ${ }^{*}, p<0.05$; ,$+ p<0.01 ; \#, p<0.001 . B$. Analysis of EEG patterns from representative single cases. In each experiment, the ${ }^{14} \mathrm{C}$-2-deoxyglucose solution $(2-D G)$ was administered intravenously after the intracerebral infusion.
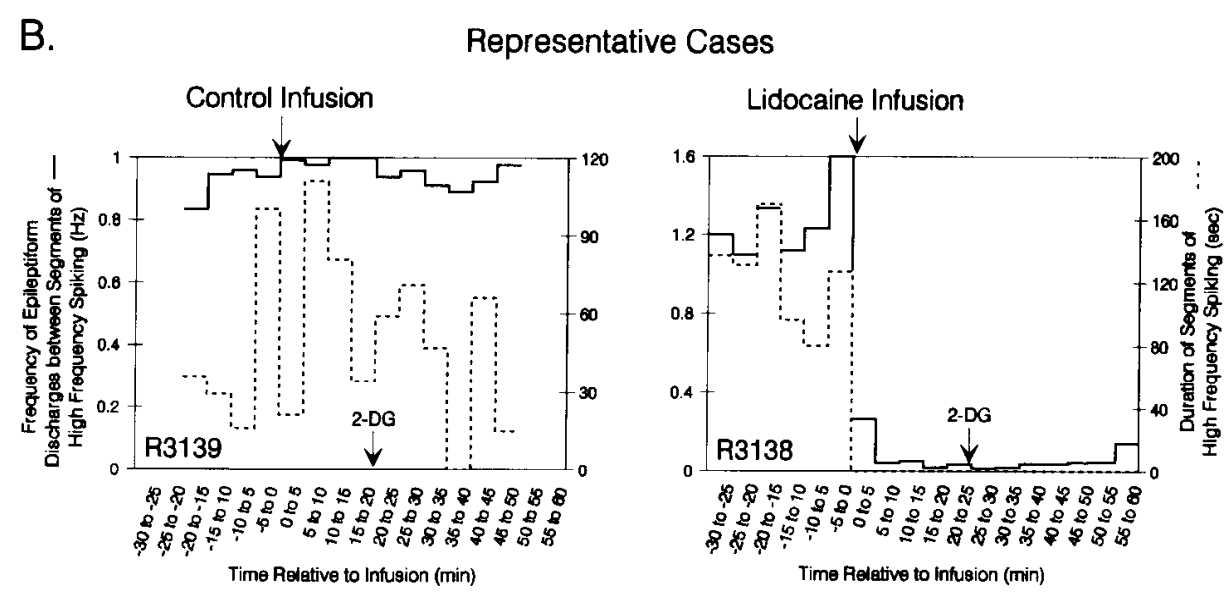

panying pattern of ${ }^{14} \mathrm{C}$-2-deoxyglucose uptake was similar to the pattern following the infusion of the vehicle solution alone, with the possible exception of the lateral amygdaloid nucleus.

In five of these seven cases, the lateral nucleus was relatively hypometabolic, when compared to the cases with infusions of the vehicle solution alone (Fig. 8). The perirhinal cortex, which is strongly interconnected with the lateral nucleus (Ottersen, 1982; Turner and Zimmer, 1984), was also hypometabolic in these same experiments. Although this result may be due in part to the cannula lesion per se, it suggests that the injected GABA agonist was effective in the lateral nucleus but not in the basal amygdaloid nucleus. It also demonstrates that deactivation of the lateral nucleus of the amygdala does not effect the expression of type III status.

\section{Infusions into the ventral hippocampal formation}

Extent of the infusions. For infusion into the ventral hippocampal formation, the cannula traversed the molecular and pyramidal cell layers of the CA1 and CA3 fields, and the lateral wing of the dentate gyrus, and the cannula tip usually abutted the pyramidal cell layer of the ventral subiculum. In the sections that were processed for peroxidase histochemistry, the ventral hippocampal formation was filled with HRP reaction product in each case (Fig. 2D). Typically, this area involved the ventral dentate gyrus, the ventral portions of the hippocampal CA fields, and the ventral subiculum, but it did not include the entorhinal or perirhinal cortex.

Effects of the infusions. In five of six cases, the infusion of 200-1000 nmol of lidocaine had a selective effect on the clinical manifestations of type III status. The usual "interictal" patterns of regular epileptiform discharges and incessant exploratory behaviors continued unabated, but the episodes of facial and forelimb clonus that characterize this level of status were suppressed (Table 2). The EEG hallmarks of facial and forelimb clonus, the discrete segments of sustained high-frequency discharges, were no longer present, such that the EEG resembled that seen in type II status (Figs. $3 C, 9$ ). This effect lasted throughout the remainder of the experiment, about an hour each case.

The pattern of ${ }^{14} \mathrm{C}$-2-deoxyglucose uptake in these cases was also similar to the pattern usually seen in type II status, except that the region of the ventral subiculum was hypometabolic (Fig. 10). All elements of the expanded anatomical substratc specifically associated with type III status were deactivated. In particular, the dentate gyrus, CA fields of the hippocampus, subiculum, the superficial parts of the entorhinal cortex, piriform cortex, and amygdala, the prefrontal cortex, and the olfactory tubercle were all deactivated after the infusions.

In one rat, an infusion of $1000 \mathrm{nmol}$ of lidocaine failed to 

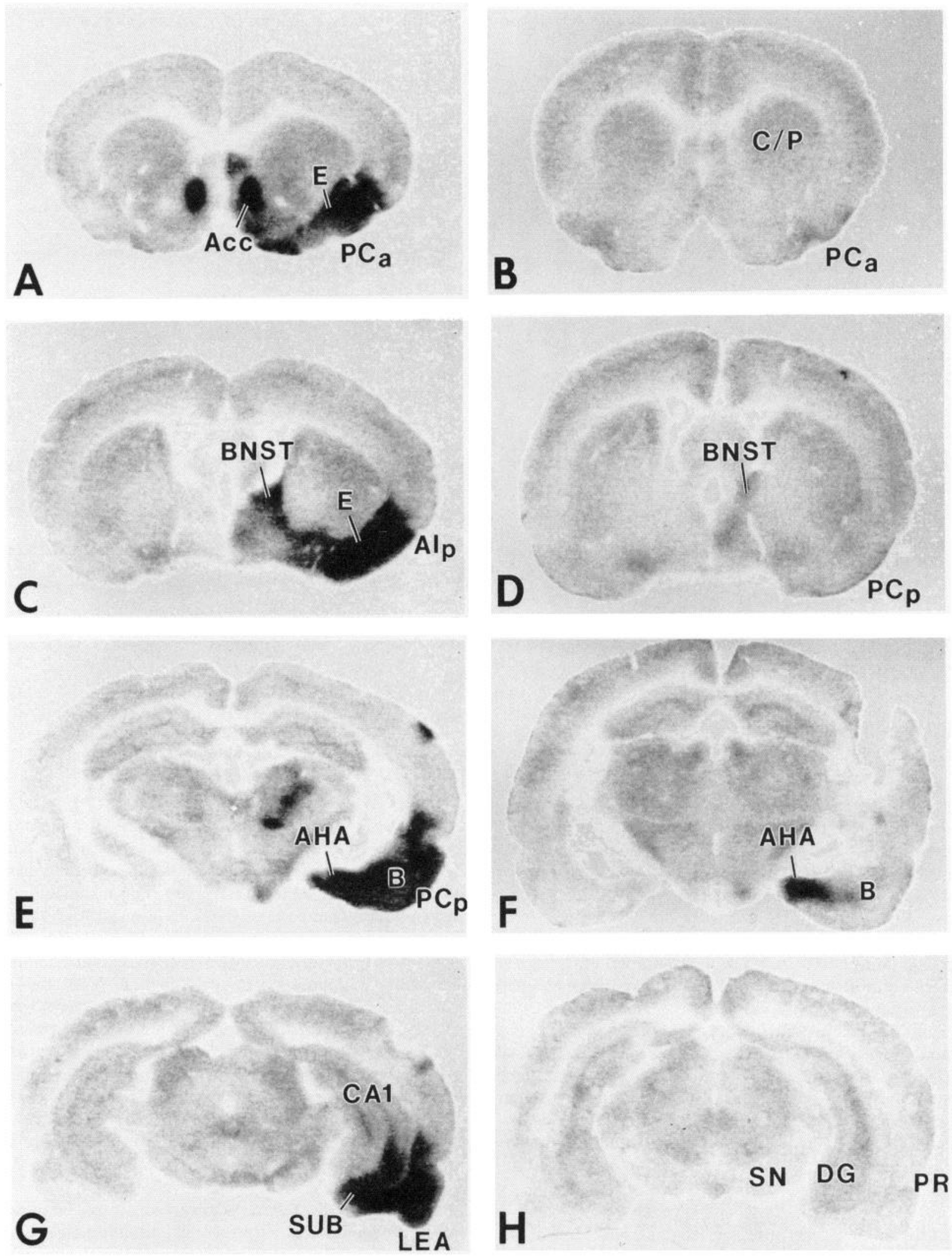

Figure 7. Patterns of ${ }^{14} \mathrm{C}$-2-deoxyglucose uptake after an infusion of $100 \mathrm{nl}$ of the vehicle alone (left column) or $200 \mathrm{nmol}$ of lidocaine in $100 \mathrm{nl}$ of solution (right column) into the basal nucleus of the amygdala during type III status. The infusion of the vehicle solutiori had little effect on the clinical manifestations of type III status, or on the typical pattern of ${ }^{14} \mathrm{C}$-2-deoxyglucose uptake. In contrast, the infusion of lidocaine deactivated the basal nucleus $(F)$ and all other anatomical structures specifically associated with type III (and type II) status. Only the amygdalohippocampal area $(F)$ and the bed nucleus of the stria terminalis $(D)$ remained active. This residual pattern of activation is identical to the pattern associated with type I status. For abbreviations, see Appendix. 

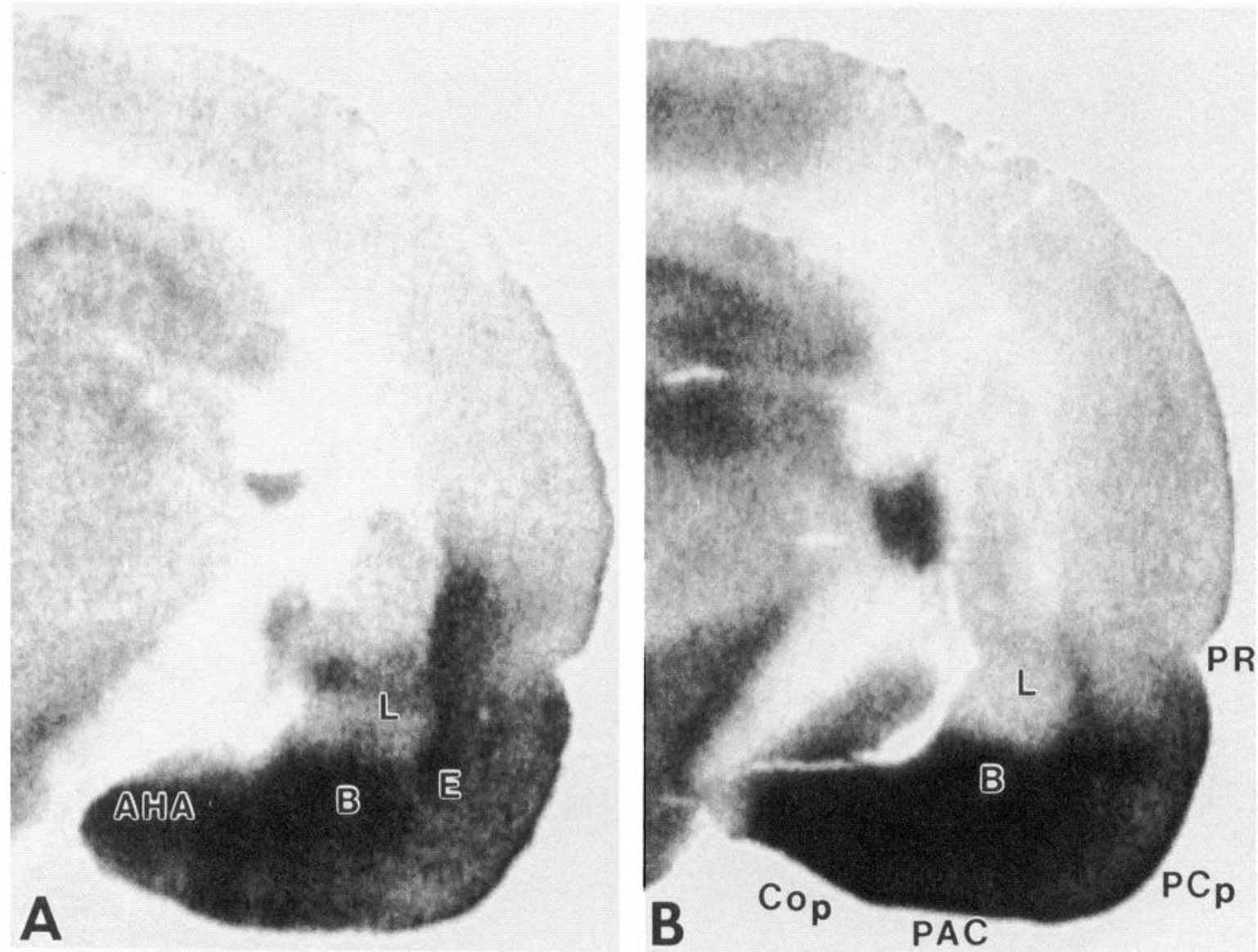

Figure 8. Coronal autoradiographic images at the level of the caudal amygdala demonstrate the patterns of ${ }^{14} \mathrm{C}$-2-deoxyglucose uptake associated with an infusion of the vehicle alone $(A)$ or muscimol $(B)$ into the basal nucleus of the amygdala during type III status. $A$, The infusion of the 100 $\mathrm{nl}$ of vehicle alone had no effect upon the level of activity within the basal nucleus $(B)$. $B$, Similarly, an infusion of $30 \mathrm{nmol}$ of muscimol in 300 $\mathrm{nl}$ of solution failed to affect the basal nucleus, but the lateral nucleus $(L)$ appears hypometabolic. For abbreviations, see Appendix.

affect type III status. Discrete episodes of facial and forelimb clonus continued to develop throughout the remainder of this experiment. In this rat, the pattern of ${ }^{14} \mathrm{C}$-2-deoxyglucose uptake was similar to the pattern usually seen in type III status, except that most of the ventral hippocampal formation was hypometabolic. All other elements of the anatomical substrate of type III status, including the entire amygdaloid complex and piriform cortex, the ventral striatum, and the prefrontal cortex, exhibited robust ${ }^{14} \mathrm{C}$-2-deoxyglucose uptake.

In each of five control experiments, the infusion of the vehicle solution alone produced no significant changes in the clinical manifestations of type III status (Fig. 9, Table 2), although some animals had fewer episodes of facial and forelimb clonus after the infusion of the vehicle solution. The pattern of ${ }^{14} \mathrm{C}$-2-deoxyglucose uptake usually associated with type III status was evident in these cases, except for a restricted region of hypometabolism surrounding the cannula track (Fig. 10).

\section{Infusions into the amygdalohippocampal area}

Extent of the infusions. In these experiments, the cannula track traversed the lateral edge of the thalamus and extended ventrally into the amygdalohippocampal area. Peroxidase reaction product was found throughout most of the amygdalohippocampal area, and in surrounding regions of the ventral-medial temporal lobe (Fig. $2 \mathrm{C}$ ). Because of the location of the amygdalohippocampal area ventral to the floor of the lateral ventricle, some leakage into the ventricle was unavoidable. In most cases, reaction product was evident in the tissue surrounding the ventricle, including the ventral-anterior portions of the dentate gyrus, hippocampal field $\mathrm{CA} 3$ and the ventral subiculum, and in the caudal-medial parts of the lateral amygdaloid nucleus.

Effects of the infusions. In five of the six rats, infusion of 800 $1000 \mathrm{nmol}$ of lidocaine into the amygdalohippocampal area transiently suppressed the development of facial and forelimb clonus and the associated segments of high-frequency discharges (Figs. 3D, 11; Table 2). This treatment had no effect on the "interictal" EEG and behavioral patterns. This effect was similar to results that followed the infusions of lidocaine into the ventral hippocampal formation during type III status, except that it lasted only about $20 \mathrm{~min}$ (mean \pm SEM was $19.8 \pm 7.1 \mathrm{~min}$ ). In the sixth animal, the infusion of $1000 \mathrm{nmol}$ of lidocaine failed to produce any changes in the clinical manifestations of type III status.

Because the ${ }^{14} \mathrm{C}$-2-deoxyglucose was infused within $10 \mathrm{~min}$ of the redevelopment of overt ictal activity, the pattern of ${ }^{14} \mathrm{C}$ 2-deoxyglucose uptake should largely reflect the resumption of the usual type III status activities, rather than the interval during which seizures with facial and forelimb clonus were suppressed. The pattern of ${ }^{14} \mathrm{C}$-2-deoxyglucose uptake was similar to the overall pattern typically seen in type III status, except that the region surrounding the amygdalohippocampal area was relatively hypometabolic (Fig. 12F). This region included the amyg- 
A.

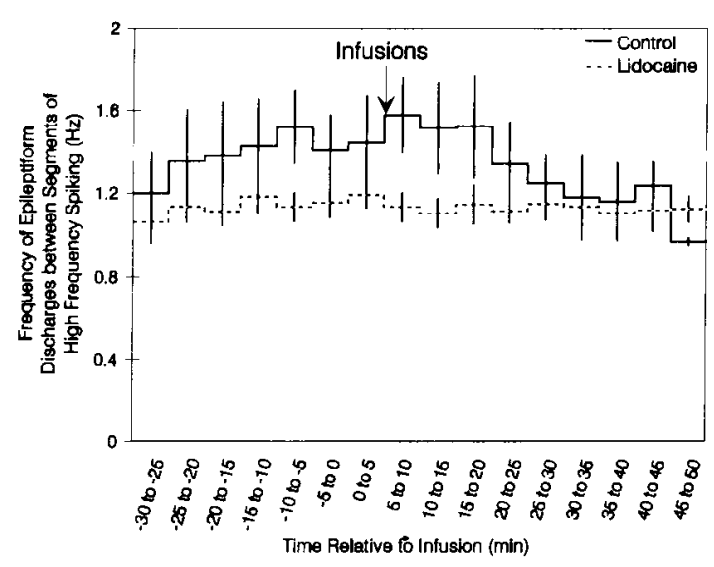

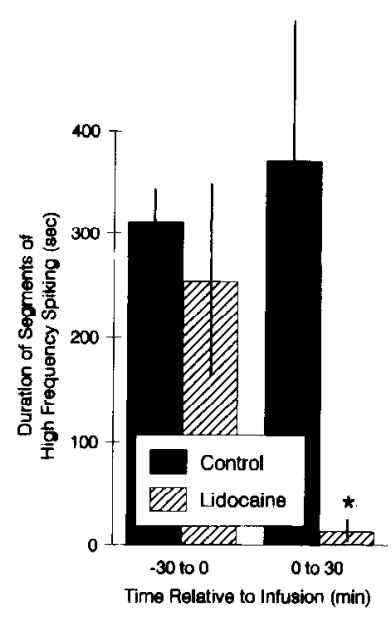

Representative Cases
B.

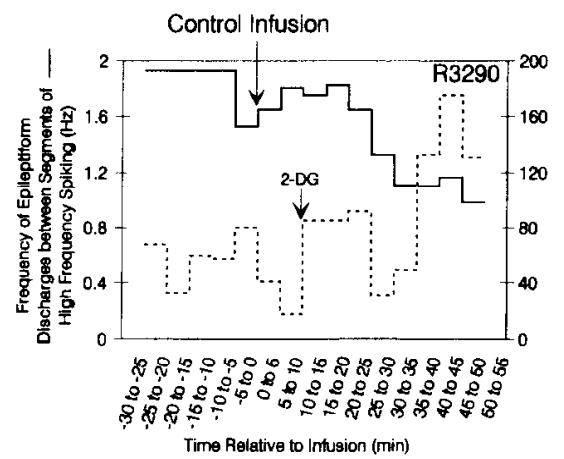

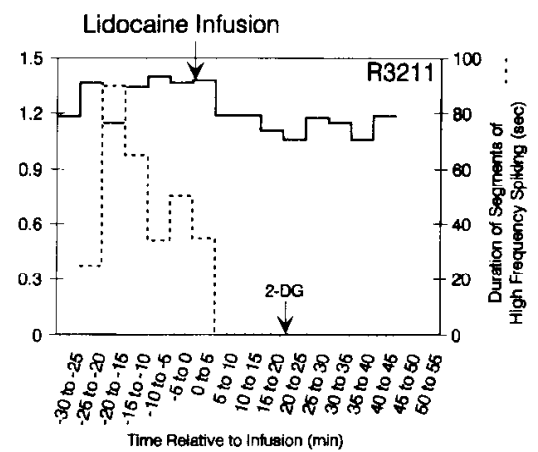

Figure 9. Analysis of EEG records from experiments in which the vehicle alone (Control, $n=5$ ) or lidocaine ( $n$ $=6$ ) was infused into the ventral hippocampal formation during type III status; the conventions are the same as in Figure 7. $A$, Summary of the results from all cases. The asterisk in the right panel indicates a significant difference $(p<0.01)$ in the duration of periods of high frequency discharges. $B$, Analysis of EEG patterns from representative single cases. In the right panel, note the selective attenuation of the periods of sustained high-frequency discharges that mark seizures with facial and forelimb clonus, without an effect upon the frequency of "interictal" epileptiform discharges. dalohippocampal area, other caudal-medial parts of the amygdaloid complex, and the extreme rostral portion of the ventral subiculum and dentate gyrus. All other elements of the anatomical substrate associated with type III status were unaffected, including the basal amygdaloid nucleus and more caudal portions of the ventral hippocampal formation.

In three control experiments, the infusion of the vehicle solution alone into the amygdalohippocampal area had no effect on the behavioral or EEG patterns of type III status (Fig. 11). The pattern of ${ }^{14} \mathrm{C}$-2-deoxyglucose uptake was similar to the pattern normally associated with type III status, except for a small region of hypometabolism immediately surrounding the cannula track (Fig. 12E).

\section{Infusions into the anterior piriform cortex}

Extent of the infusions. The infusions were targeted specifically at the site in the deep layers of the anterior piriform cortex that is especially sensitive to the application of chemical convulsants (i.e., "area tempestas"; Piredda and Gale, 1985; Gale and Browning, 1986). This site was filled with peroxidase reaction product from the injection in each experiment (Fig. 2A). Typically, the area of diffusion of the reaction product involved the dorsal endopiriform nucleus, as well as layers II and III of the anterior piriform cortex as far caudal as the genu of the corpus callosum. Reaction product was found to a variable extent along the cannula track through the lateral precentral area, the dorsal and lateral orbital areas, and the agranular insular area in the depths of the rhinal sulcus.

Effects of the infusions. The infusion of $1000 \mathrm{nmol}$ of lidocaine or $50 \mathrm{nmol}$ of muscimol produced no changes in the behavioral or EEG manifestations of type III status (Table 2). The effect of these infusions on the overall pattern of ${ }^{14} \mathrm{C}$-2-deoxyglucose uptake was limited to deactivation of a large region in the rostral forebrain that typically involved the lateral part of the anterior olfactory nucleus, most of the anterior piriform cortex, the subjacent endopiriform region, and the overlying portions of the agranular insular cortex (Fig. 13B). This region of deactivation included the "area tempestas." At more caudal levels, the posterior piriform cortex, and posterior portions of the endopiriform nuclei were unaffected (Fig. 13D,F). All other elements of the widespread anatomical substrate associated with type III status remained active, including the basal nucleus of the amygdala and the ventral hippocampal formation.

The infusion of the vehicle solution alone into the anterior piriform cortex had no effect on the clinical manifestations of type III status in each of three cases (Table 2). There were no changes in the frequency of epileptiform discharges or the duration of the segments of high-frequency spiking. The pattern of ${ }^{14} \mathrm{C}$-2-deoxyglucose uptake was similar to the pattern typically associated with type III status, except for the hypometabolic region around the cannula track (Fig. 13A). 

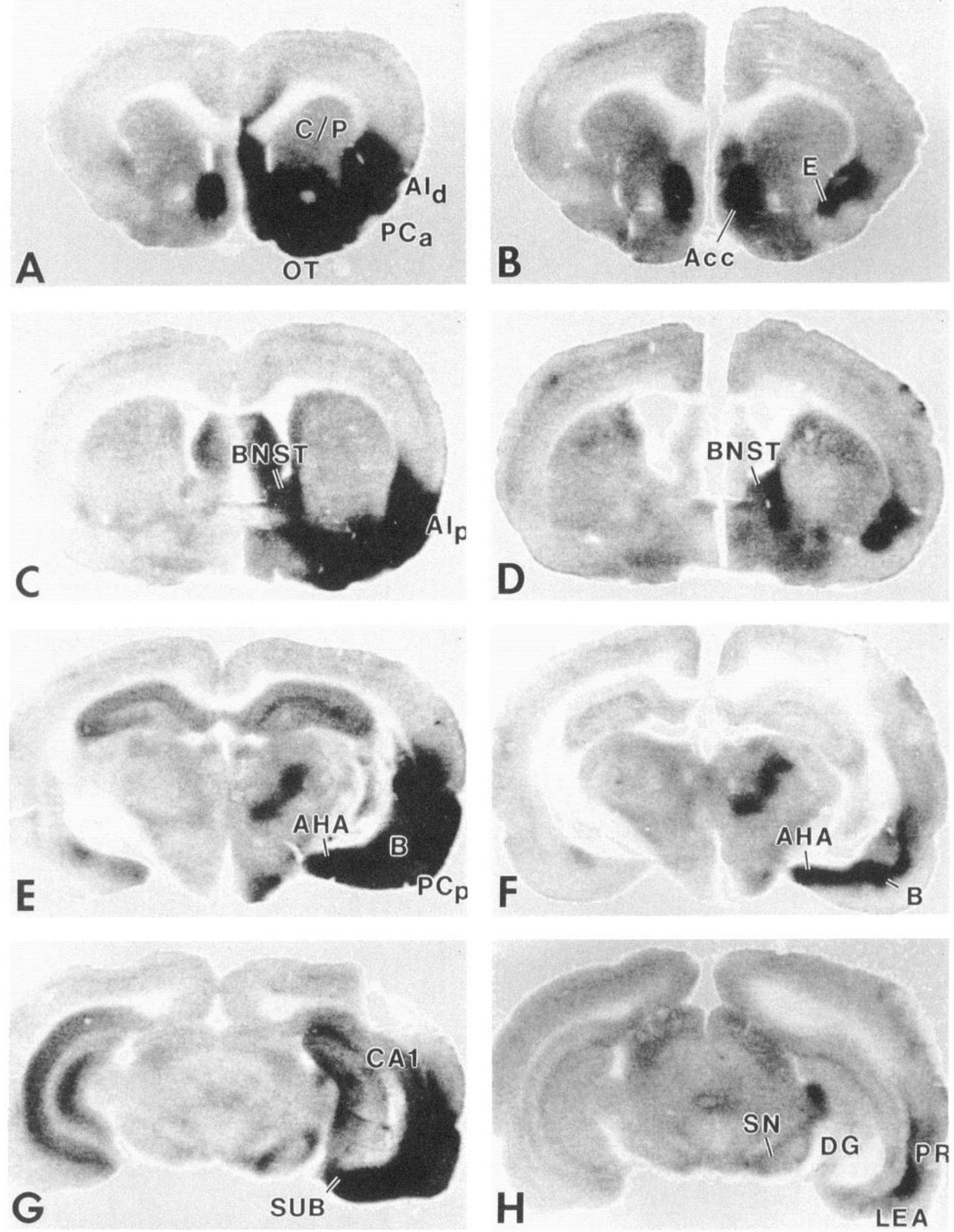

Figure 10. Patterns of ${ }^{14} \mathrm{C}-2$-deoxyglucose uptake after an infusion of $500 \mathrm{nl}$ of the vehicle alone (left column) or $400 \mathrm{nl}$ of a solution with 800 nmol of lidocaine (right column) into the ventral hippocampal formation during type III status. The infusion of the vehicle solution had little effect on the clinical manifestations of type III status, or on the overall pattern of ${ }^{14} \mathrm{C}$-2-deoxyglucose uptake, except for a restricted region of hypometabolism within the hippocampus surrounding the track of the inner cannula $(G)$. In contrast, the infusion of lidocaine deactivated the ventral hippocampal formation $(H)$, and other anatomical structures that are specifically associated with type III status. The remaining pattern of activation is similar to the pattern seen in type II status. For abbreviations, see Appendix. 
Infusions into the Amygdalohippocampal Area during Type III Status

A.

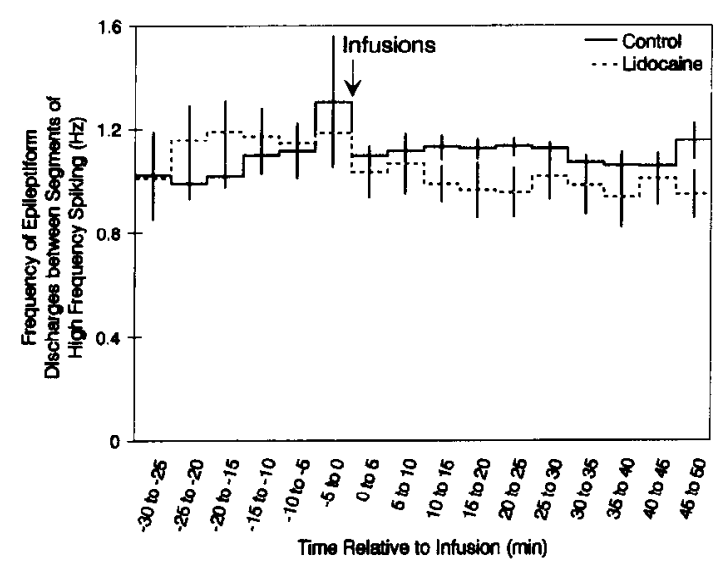

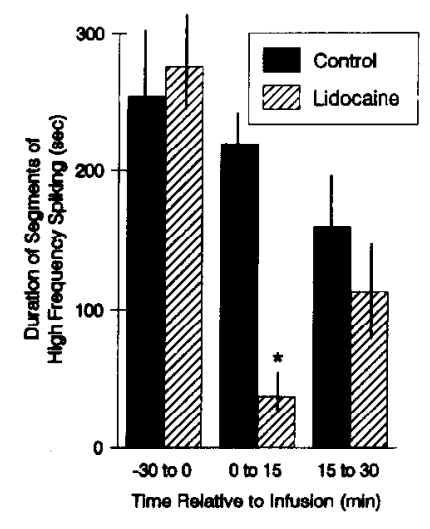

B.

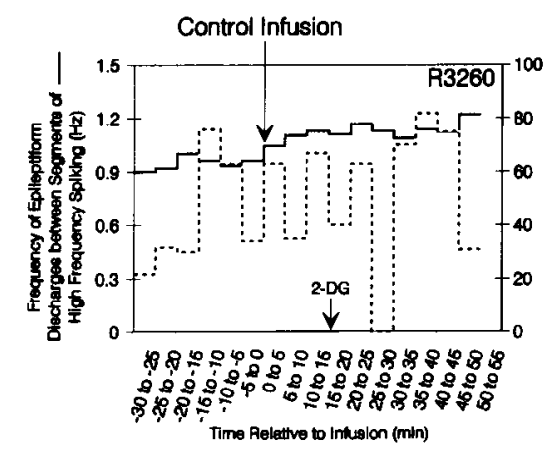

Representative Cases

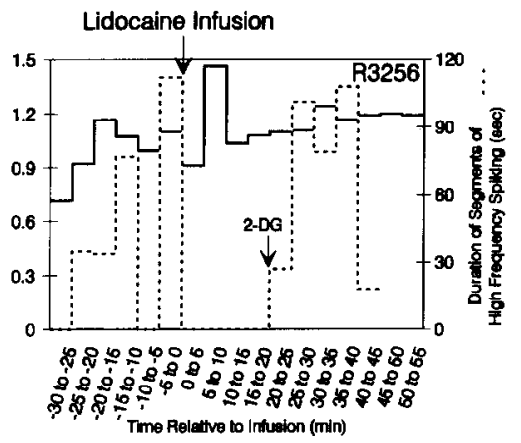

Figure 11. Analysis of EEG records from experiments in which the vehicle alone (Control, $n=3$ ) or lidocaine ( $n$ $=6$ ) was infused into the amygdalohippocampal area during type III status; the conventions are the same as in Figure 7. $A$, Summary of the results from all cases. In the right panel, the asterisk identifies a significant difference $(p<$ 0.01 ) in the duration of the segments of high-frequency spiking during the first $15 \mathrm{~min}$ after the infusion. $B$, Analysis of EEG patterns from representative cases with infusion of the vehicle alone (left) or lidocaine (right). In the right panel, note the selective, transient suppression of the periods of high-frequency discharge and accompanying seizurcs with facial and forclimb clonus for $20 \mathrm{~min}$ following the infusion of lidocaine, without an effect upon the frequency of "interictal" epileptiform discharges.

\section{Discussion}

In the preceding article (White and Price, 1993), the neural substrates of subconvulsive and convulsive levels of limbic status epilepticus were identified, with the aid of ${ }^{14} \mathrm{C}$-2-deoxyglucose autoradiography and Fos immunocytochemistry. Those data indicate that the amygdalohippocampal area is the focus of the most restrictive form of limbic status, typc I. The other, more expansive forms of status, types II and III, also involve the amygdalohippocampal area, but engage more widely distributed structures throughout the ventral forebrain. The anatomical relationships among these structures suggest that the basal nucleus of the amygdala and the ventral hippocampal formation should be important for the generation and expression of these more widespread seizure states. The present experiments were designed to identify the source or sources of the epileptiform activity in type II and type III status, with special emphasis on the roles of the basal nucleus and the ventral hippocampal formation. The major findings are that the basal nucleus of the amygdala is the primary epileptogenic focus of both seizure states, and that the ventral hippocampus is additionally involved in the development of sustained ictal discharges with facial and forelimb clonus.

\section{Generation of limbic status epilepticus}

From the results of these studies, a model of the neural basis of different levels of limbic status epilepticus can be proposed (Fig. 14). In this model, the amygdalohippocampal area and the basal nucleus of the amygdala are the epileptogenic foci of limbic status. Type I status is associated with seizure activity in the amygdalohippocampal area, as described in the preceding article (White and Price, 1993). As demonstrated by the present results, type II and type III status involve additional epileptiform activity emanating from the basal amygdaloid nucleus, which can be considered the primary focus of these more expansive forms of status epilepticus. Type II status can be described relatively simply as a seizure state existing within the basal amygdaloid nucleus and several closely related parts of the ventral forebrain. Type III status is based upon type II status, but with the recurrent expansion of the anatomical substrate to involve widespread limbic and extralimbic structures. The rampant propagation of epileptiform activity throughout this expanded substrate is manifested as overt forebrain seizures marked by discrete episodes of high-frequency EEG discharges and facial and forelimb clonus. The involvement of the ventral hippocampal formation is crucial for the recruitment of the more expansive anatomical substrate and the development of the recurrent ictal events.

In type II and type III status, the concurrent activation of both the amygdalohippocampal area and the basal amygdaloid nucleus raises the possibility that these forms of status require the ongoing activation of the amygdalohippocampal area, which in some way drives or facilitates activity in the basal nucleus. However, the results of the experiments with lidocaine argue against this possibility. Deactivation of the basal nucleus fails to affect activity within the amygdalohippocampal area. The 

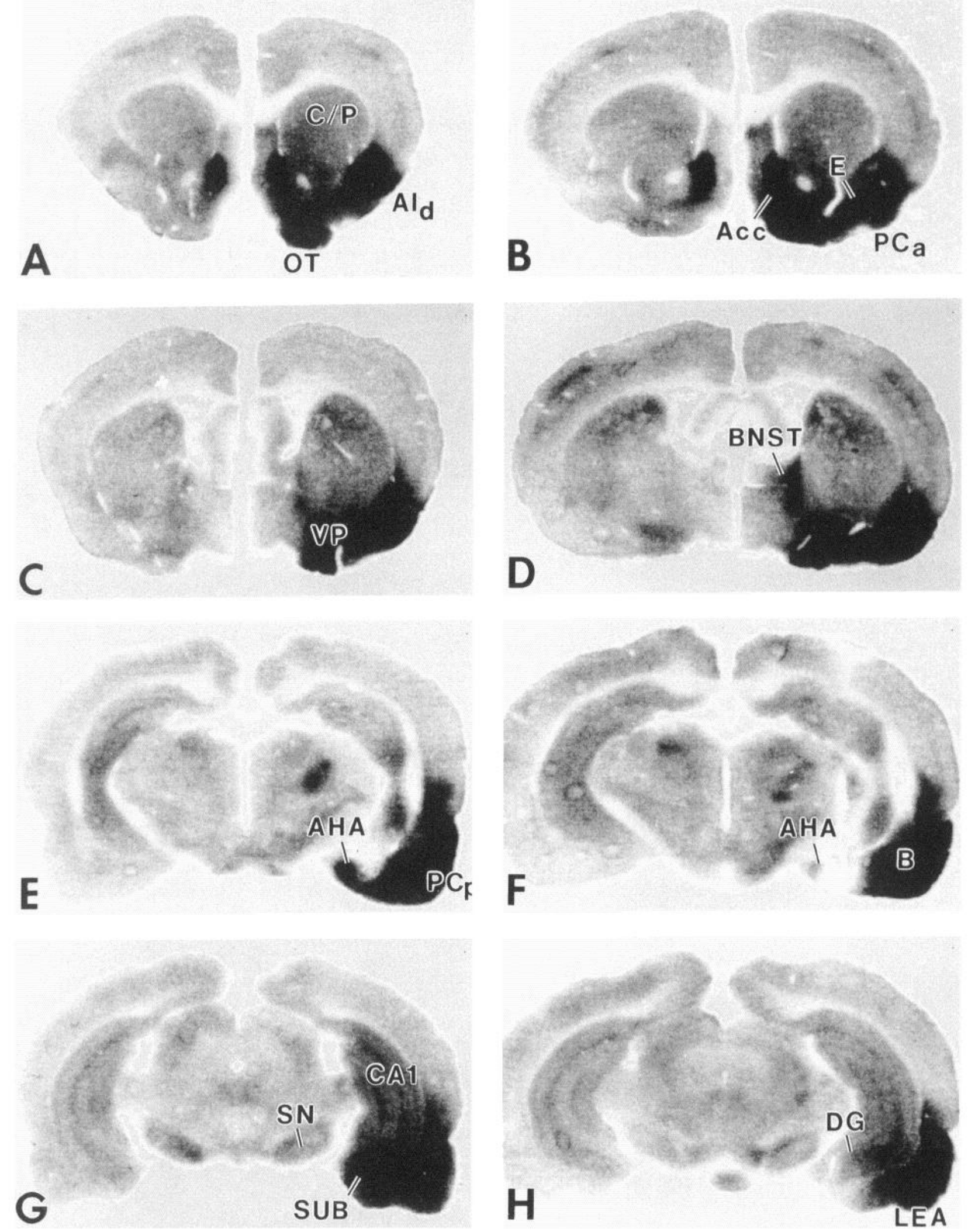

Figure 12. Patterns of ${ }^{14} \mathrm{C}$-2-deoxyglucose uptake after an infusion of $400 \mathrm{nl}$ of the vehicle alone (left column) or $400 \mathrm{nl}$ of a solution with 800 nmol of lidocaine (right column) into the amygdalohippocampal area during type III status. The infusion of the vehicle solution had little effect on the clinical manifestations of type III status, or on the overall pattern of ${ }^{14} \mathrm{C}$-2-deoxyglucose uptake, except for a restricted region of hypometabolism within the amygdalohippocampal area surrounding the track of the inner cannula $(E)$. Although the infusion of lidocaine transiently suppressed the development of seizure activity with facial and forelimb clonus, this suppression was not resolved in the overall pattern of ${ }^{14} \mathrm{C}$-2-deoxyglucose uptake (see text for details). Except for the amygdalohippocampal area and surrounding regions within the rostral anterior-medial temporal lobe that were deactivated $\left(F\right.$ and $H$ ), the overall pattern of ${ }^{14} \mathrm{C}$-2-deoxyglucose resembles the pattern usually seen in type III status. For abbreviations, see Appendix. 


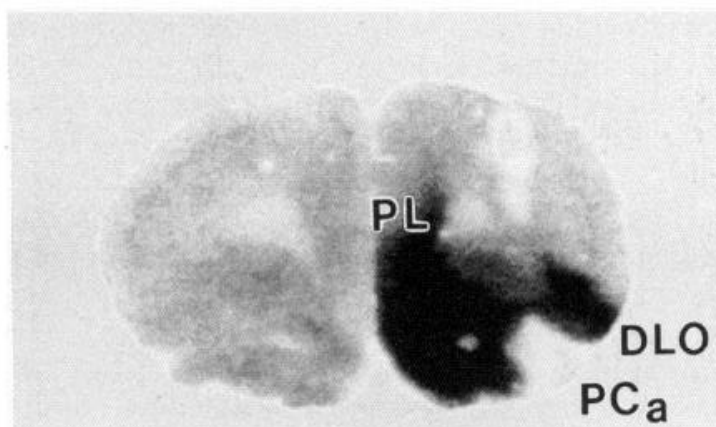

A
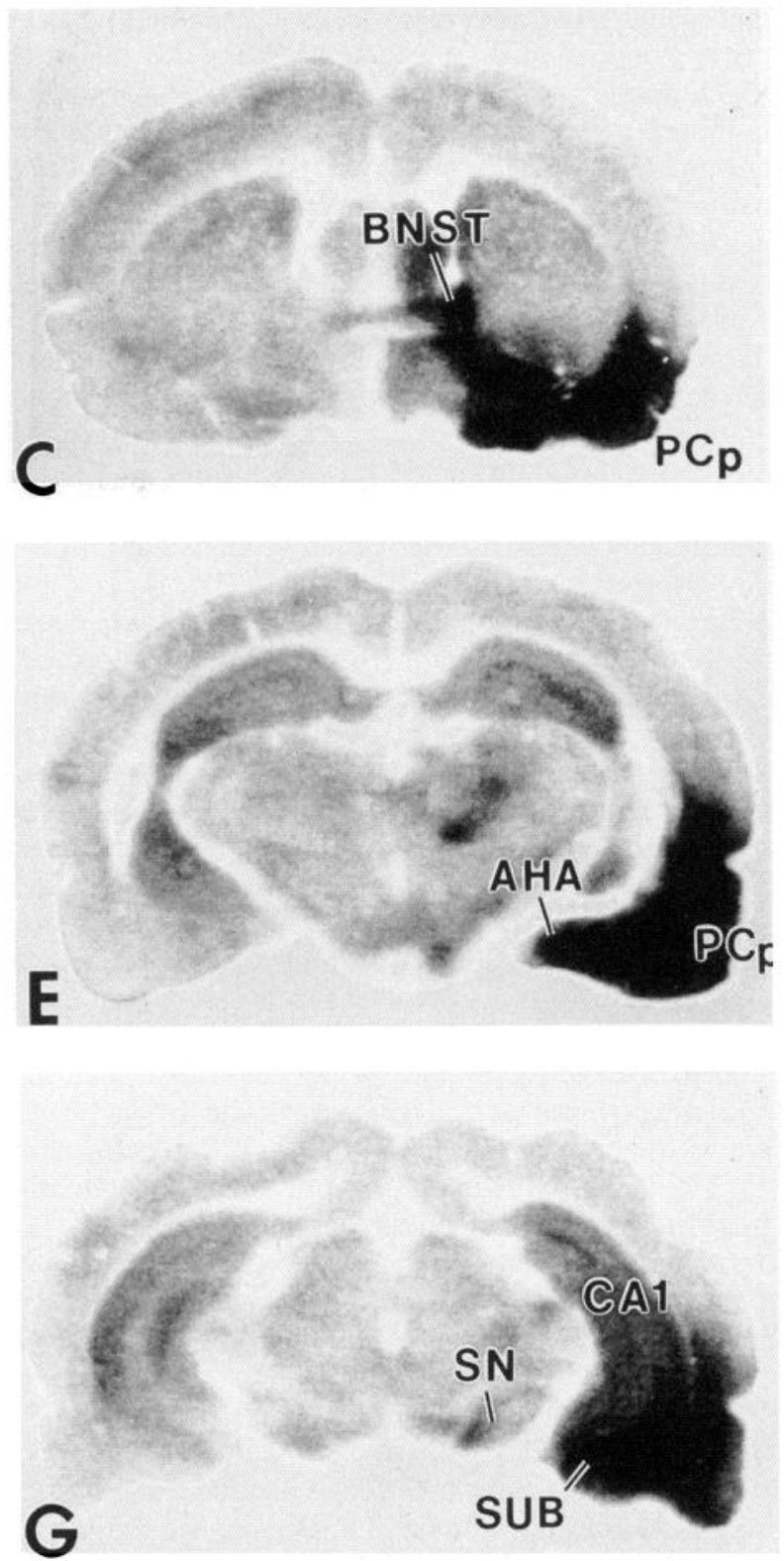
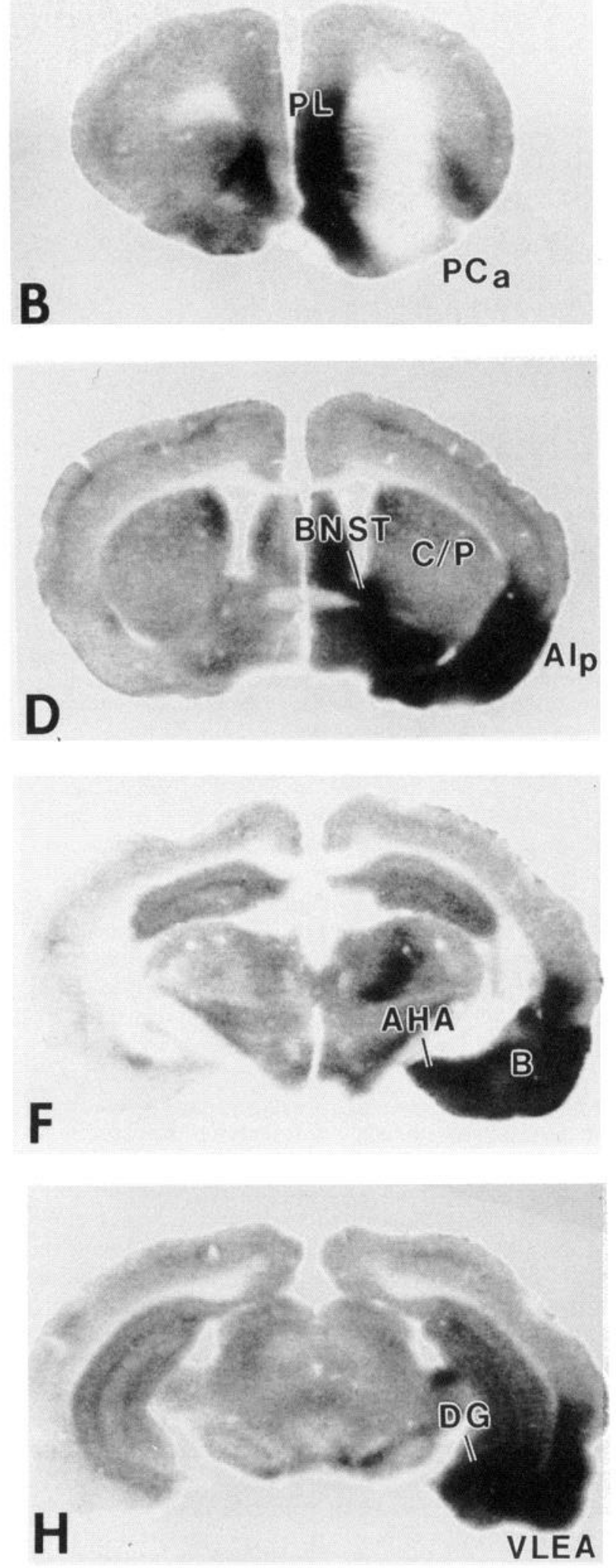

Figure 13. Patterns of ${ }^{14} \mathrm{C}$-2-deoxyglucose uptake after an infusion of $400 \mathrm{nl}$ of the vehicle alone (left column) or $1000 \mathrm{nmol}$ of lidocaine in 500 $\mathrm{nl}$ of solution (right column) into the anterior piriform cortex during type III status. The infusion of the vehicle solution had little effect on the clinical manifestations of type III status, or on the overall pattern of ${ }^{14} \mathrm{C}$-2-deoxyglucose uptake, except for a restricted region of hypometabolism within the anterior piriform cortex surrounding the track of the inner cannula $(A)$. Similarly, the infusion of lidocaine had no effect upon the clinical expression of type III status, despite the large region of hypometabolism surrounding the site of infusion in the ventral-lateral forebrain $(B)$. This region, which contains "area tempestas," involved the anterior parts of the dorsal endopiriform nucleus and piriform cortex, and rostral insular regions within the depths of the rhinal sulcus. Elsewhere, the overall pattern of ${ }^{14} \mathrm{C}$-2-deoxyglucose resembles the pattern usually seen in type III status. For abbreviations, see Appendix. 


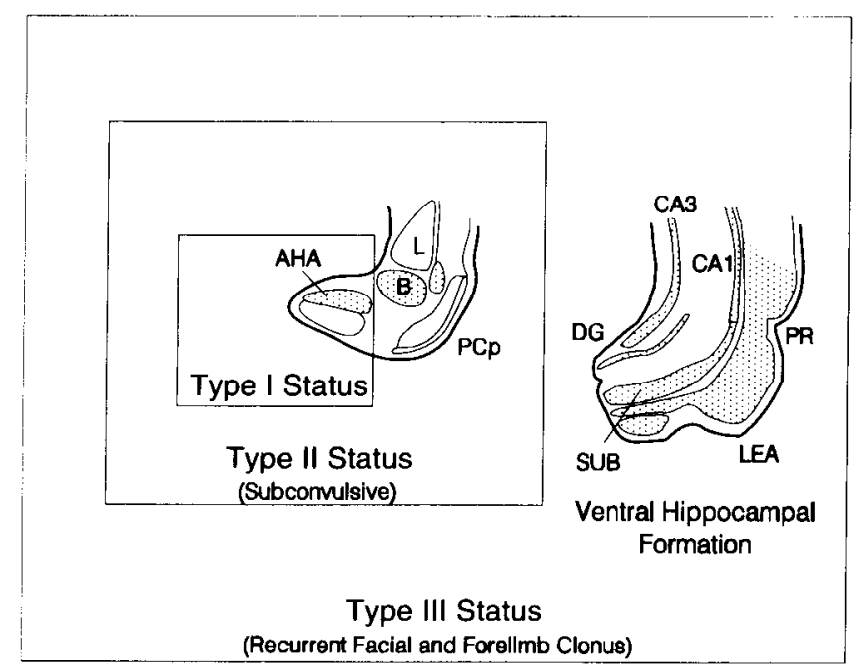

Figure 14 . Schematic modei for the generation of three types of limbic status epilepticus. Shading represents seizure-related activity, and the concentric boxes indicate that status types II and III include all the defining characteristics of types I and II, respectively. The epileptogenic focus of type I status is the amygdalohippocampal area. Status types II and III involve this structure and require additional participation of the basal nucleus of the amygdala. Thus, the basal nucleus is the epileptogenic focus of the more widespread levels of status epilepticus. During type III status, the recurrent episodes of seizures with facial and forelimb clonus involve the additional recruitment of the ventral hippocampal formation. For abbreviations, see Appendix.

converse is also true; deactivation of the amygdalohippocampal area is of no significance to the basal nucleus. Thus, these two amygdaloid structures appear to serve independently to generate status activity. Such apparent functional independence is consistent with the lack of prominent or widespread connections between these amygdaloid nuclei (Krettek and Price, 1978; Ottersen, 1982; Canteras and Swanson, 1992; White, 1992). The amygdalohippocampal area may be the forebrain structure with the lowest threshold for the induction of status activity, but its ability to recruit and interact with other potential epileptogenic foci is inconsequential.

In contrast, the basal amygdaloid nucleus has the capacity to engage a much larger constellation of structures, with the consequent development of frank seizures involving facial and forelimb clonus. Previous metabolic and electrophysiological studies have suggested that the recruitment of the ventral hippocampal formation may be necessary for the elaboration of such widespread scizurc activity (Collins et al., 1983; Stringer and Lothman, 1989, 1990, 1992; Stringer et al., 1989, 1991). In particular, the development of kindled limbic-motor seizures is associated with the appearance and lengthening of "maximal dentate activation," an electrophysiological marker for the recurrent activation of hippocampal and parahippocampal structures (Stringer et al., 1991; Stringer and Lothman, 1992). The results of the present experiments with lidocaine lend further support to this hypothesis, but they do not support a role for the ventral hippocampal formation in the generation of subconvulsive levels of status (i.e., types I and II).

Deactivation of the ventral hippocampal formation with lidocaine selectively prevents the recurrent development of sustained seizure activity, without the attenuation of the "interictal" behavioral and EEG manifestations. The associated pattern of ${ }^{14} \mathrm{C}$-2-deoxyglucose uptake confirms that the ventral hippo- campal formation was deactivated together with the entire expanded anatomical substrate that is specifically associated with type III status. Two major conclusions should be drawn from these findings. First, the ventral hippocampal formation is not the source of the interictal epileptiform activity. Second, the ventral hippocampal formation is preferentially recruited in the dissemination of epileptiform activity throughout the ventral forebrain and the consequent development of facial and forelimb clonus. Taken together, these two conclusions indicate that the ventral hippocampal formation is not a "focus" of status epilepticus in these seizure states, but is involved in the propagation of epileptiform activity throughout the ventral forebrain. This interpretation of the function of the ventral hippocampal formation in the pathogenesis of status epilepticus differs somewhat from that of Lothman and his colleagues, especially in relation to their "score 4" stage of status epilepticus, which appears to correspond to type III status (reviewed by Lothman, 1990; Lothman et al., 1991; VanLandingham and Lothman, 1991a,b). In their view, the ventral hippocampal formation is the "key element involved in initiating and maintaining" limbic status epilepticus (Lothman et al., 1989). Our results indicate that the ventral hippocampal formation is involved in the maintenance of type III status, but only in that the rccruitment of this complex is associated with the widespread propagation of ictal activity throughout the ventral forebrain; the hippocampus itself does not provide the focal drive for this level of status.

These conclusions are based upon the results of five of six experiments in which deactivation of the ventral hippocampal formation converted type III status to type II. The remaining experiment produced a different result; infusion of lidocaine into the ventral hippocampal formation failed to suppress the recurrent development of seizures with facial and forelimb clonus. The associated pattern of ${ }^{14} \mathrm{C}$-2-deoxyglucose uptake in this case confirmed the deactivation of the ventral hippocampal formation, but failed to reveal any change in the remaining structures that underlie type III status. Although the ventral hippocampal formation is preferentially involved in the dissemination of seizure activity, this result indicates that sustained ictal discharges may develop and propagate without its recruitment if the level of epileptiform activity involves a sufficient "mass" of forebrain structures. This view is consistent with recent studies that have emphasized the importance of the entorhinal, perirhinal, and posterior piriform cortical regions in the development of kindled limbic-motor seizures (McIntyre et al., 1992; McIntyre and Kelley, 1993). Thus, the recruitment of the larger anatomical substrate of type III status, rather than the activation of the ventral hippocampal formation per se, is associated with the onset and maintenance of limbic seizure activity and the associated clonic motor manifestations (see White and Price, 1993).

\section{Mechanisms of epileptogenesis}

\section{$G A B A$ "fading" and glutamatergic facilitation}

It is well known from other experimental models of complex partial seizures that the basal nucleus of the amygdala is particularly prone to the devclopment of focal seizure activity (Goddard et al., 1969; Wada and Sato, 1974; Tremblay et al., 1983). The results of the experiments with the $\mathrm{GABA}_{\mathrm{A}}$ receptor agonist muscimol suggest that a decrease in GABAergic inhibition may play a role in epileptogenesis within the basal nucleus. In contrast to lidocaine, muscimol was ineffective in deactivating the basal nucleus during type II and type III status 
or in attenuating either seizure state. The amounts of muscimol that were used deactivated the anterior piriform cortex during type III status, and were far greater than those that have been used in other studies to produce pharmacological deactivation of local brain regions in unanesthetized animals (e.g., Gale, 1985; Morimoto et al., 1986; Martin, 1991). Thus, it is unlikely that the ineffectiveness of muscimol in the basal amygdaloid nucleus can be explained by inadequate local concentration of the drug.

A more likely alternative explanation is that widespread status activity (i.e., types II and III) is associated with a dysfunction of synaptic inhibition mediated by $\mathrm{GABA}_{\mathrm{A}}$ receptors within the basal amygdaloid nucleus. The sustained seizure activities during the period of electrical stimulation (i.e., the period of status induction) may serve to produce a "rundown" of responses mediated by $\mathrm{GABA}_{\mathrm{A}}$ receptors within the basal nucleus, and possibly within other structures. The precise mechanisms that would underlie this effect are unknown, but they should operate within the period of $30-60 \mathrm{~min}$ that is required to induce status epilepticus with electrical stimulation (McIntyre et al., 1982; Lothman, 1990; White and Price, 1993). The concurrent facilitation of NMDA receptor-mediated excitatory neurotransmission and the subsequent rise in intracellular calcium concentrations during this time may further exacerbate the loss of inhibitory tone and amplify excitatory activity within the basal nucleus (see Chen et al., 1990; Rainnie et al., $1991 \mathrm{a}, \mathrm{b}$ ).

Indeed, Rainnie et al. (1991a,b) speculated that any enhancement in NMDA receptor activity, such as with marked depolarization or reduction in the activity of inhibitory interneurons, is likely to have profound effects on the excitability and firing patterns of principal amygdaloid neurons. The importance of NMDA receptor activation for the induction of seizure activity was demonstrated in a previous study in which the systemic administration of low doses of noncompetitive NMDA receptor antagonists (either ketamine or MK-801) prevented the development of sustained seizure activity during persistent electrical stimulation of the amygdala (White et al., 1988; L. E. White and J. L. Price, unpublished observations). In addition, intranuclear projections are distributed extensively throughout the basal nucleus (Krettek and Price, 1978; McDonald, 1982; White, 1992), and experiments with the "neurotransmitter-specific" retrograde tracer, ${ }^{3} \mathrm{H}$-D-aspartate, indicate that this associational system is largely glutamatergic (White, 1992). Such a system would provide a powerful substrate for the development and reverberation of excitatory glutamatergic activity within the basal amygdaloid nucleus.

A similar proposal has been put forward by Kapur, Lothman, and their colleagues to explain the development of status epilepticus during the continuous electrical stimulation of the ventral hippocampal formation (Kapur and Lothman, 1989; Kapur et al., 1989; Lothman, 1990). They found that recurrent seizures caused a significant reduction in the amplitude of paired-pulse inhibition in the CAl regions of the hippocampus, which was interpreted to indicate acute deterioration of GABAergic inhibition (Kapur et al., 1989). Several other studies have also supported the general notion of "GABAergic fading" as a plausible mechanism for epileptogenesis (Ben-Ari et al., 1979; Krnjevic, 1983; Roberts, 1984; Houser et al., 1986; Sloviter, 1991a,b).

\section{Cholinergic facilitation}

It is also likely that cholinergic influences contribute to the induction of status epilepticus, and to the predisposition of both the amygdalohippocampal area and the basal amygdaloid nucleus to epileptogenesis. Amygdaloid injection of cholinergic agonists or inhibitors of AChE produces a syndrome that includes several seizure-related phenomena, including wet-dog shakes, facial and forelimb clonus, and the apparent induction of status epilepticus (Olney et al., 1983; Turski et al., 1983, 1989; McDonough et al., 1987). In addition, Buterbaugh et al. (1986) demonstrated that subconvulsive doses of the muscarinic agonist pilocarpine facilitated the development of status epilepticus in amygdala-kindled rats, after the application of a brief stimulus train that would otherwise produce a self-limiting afterdischarge. In this model, the systemic administration of scopolamine, a muscarinic antagonist, prevented the induction of status epilepticus, but failed to terminate the seizure activity after initiation. These results are consistent with other findings that indicate cholinergic mechanisms may facilitate the induction of seizures, but are not crucial for the maintenance of sustained seizure activity (Olney et al., 1986; Clifford et al., 1987; Turski et al., 1989).

With these pharmacological studies in mind, it is highly suggestive that the amygdalohippocampal area and the basal amygdaloid nucleus have a striking concentration of ChAT, the enzyme that synthesizes $\mathrm{ACh}$, and $\mathrm{AChE}$ (Ben-Ari et al., 1977; Hellendall et al., 1986). The activity of ChAT in the amygdalohippocampal area and the basal nucleus is at least twice as great as in any other part of the amygdala, except layer II of the nucleus of lateral olfactory tract (Hellendall et al., 1986), which is also active during type II and type III status. The cholinergic input to the amygdala arises from cells in the subpallidal and peripallidal parts of the magnocellular basal forebrain that receive fibers from the amygdala and are activated during the period of status induction (Woolf and Butcher, 1982; Carlsen el al., 1985). An important function of $\mathrm{ACh}$ is to increase the excitability of neurons by reducing voltage- and calcium-dependent potassium currents, such as the M-current (Adams et al., 1980; Benardo and Prince, 1982). Such facilitatory effects on the excitability of neurons could obviously contribute to the initiation of seizure activity within the amygdalohippocampal area and the basal amygdaloid nucleus.

\section{The role of anterior piriform cortex in status epilepticus}

The dorsal endopiriform nucleus and the overlying superficial layers of the piriform cortex are prominently involved in the expression of type III status, and the endopiriform nucleus also participates in type II status (White and Price, 1993). The anterior portion of this region was targeted for deactivation during type III status, because of its possible role in epileptogenesis (Gale, 1988; McIntyre and Plant, 1989; Stripling and Patneau, 1990). Gale and her coworkers have described a discrete site deep to the anterior piriform cortex, which they termed "area tempestas," from which convulsive limbic-motor seizures can be induced pharmacologically with picomolar amounts of bicuculline, kainic acid, or carbachol (Piredda and Gale, 1985; Gale and Browning, 1986). More recently, elegant electrophysiological studies in vitro have demonstrated that multipolar and pyramidal neurons within the dorsal endopiriform nucleus, adjacent claustral regions, and layer III of the piriform cortex have the capacity to generate "epileptiform" EPSPs (i.e., high-amplitude, long-latency potentials that are synchronized between simultaneously recorded pairs of cells) (Hoffman and Haberly, 1989, 1991; Tseng and Haberly, 1989a,b).

Notwithstanding, deactivation of the anterior piriform cortex 
during type III status has no effect on the clinical expression of either seizure state. Both the behavioral and the EEG manifestations of each type of status continued without abatement, even though the ${ }^{14} \mathrm{C}$-2-deoxyglucose autoradiograms indicated that the region was effectively deactivated. The participation of the anterior piriform cortex is therefore not essential for the expression of type II or type III status. These findings are consistent with other reports that have indicated that the anterior piriform cortex may not have a special role in the generation or propagation of epileptiform activity within the forebrain (Cain et al., 1988; Ludvig and Moshé, 1988; Wahnschaffe and Löscher, 1990). Thus, the apparent extraordinary sensitivity of the anterior piriform cortex to chemical convulsants should not be generalized to imply that this structure is of primary importance in the generation and maintenance of seizure activity in status epilepticus, or in other experimental models.

\section{Clinical applications}

These experimental studies in the rat raise the issue of whether the amygdalohippocampal area and the basal amygdaloid nucleus play a principal role in the generation or expression of individual complex partial seizures (i.e., self-limiting seizures, not status epilepticus) in patients with mesial temporal lobe epilepsy. The weight of current clinical and experimental evidence indicates that the amygdala may be the source of some, but not all, complex partial seizures. Of particular relevance to this question are recent neuropathological studies with modern neuroanatomical and neurochemical methods that have facilitated the recognition of two broad groups of patients with mesial temporal lobe epilepsy: those with anterior temporal masses (tumor-related group), and those without (cryptogenic group) (de Lanerolle et al., 1989; de Lanerolle and Spencer, 1991). The tumor-related group is heterogeneous with regard to the nature of the alien tissue mass, although the masses are often found in the amygdaloid complex (Bruton, 1988; de Lanerolle and Spencer, 1991; Feindel et al., 1991). Importantly, the anterior hippocampal formation in this group tends to be free of pathological abnormalities (de Lanerolle et al., 1989; de Lanerolle and Spencer, 1991). In marked contrast, in the cryptogenic group the hippocampal formation shows a variety of disturbances, including neuronal cell loss and the sprouting of specific intrinsic fiber systems (Sutula et al., 1989; de Lanerolle et al., 1989; Houser et al., 1990; de Lanerolle and Spencer, 1991). These neuropathological observations suggest that the anatomical focus and/or the mechanisms of seizure initiation may be fundamentally different in these two groups of patients (de Lanerolle et al., 1989). It is possible that the underlying mechanisms of seizure initiation preferentially involve the amygdala in the tumor-related group, while the anterior hippocampal formation is the primary epileptogenic focus in the cryptogenic group (see also Babb et al., 1984a,b). These speculations are consistent with a recent study by Goldring et al. (1992) of patients who underwent selective anterior temporal lobectomy with minimal removal of the amygdaloid complcx. They report a high incidence of beneficial clinical outcome for patients with hippocampal sclerosis, while a positive outcome was less likely for patients without frank hippocampal sclerosis.

Nevertheless, the possibility that complex partial seizures may arise from the amygdala, even in the absence of an intra-amygdaloid mass, should not be dismissed. For biophysical reasons, ictal events that originate within the amygdala may not be faithfully represented in standard depth EEG configurations (Gloor,
1987, 1992). Unlike the highly laminar cytoarchitecture of the Ammon's horn region of the hippocampus, the irregular arrangement of neurons within the deep amygdaloid nuclei does not favor the generation of powerful open electrical fields. Thus, the true incidence of ictal events that originate within the amygdala may be difficult to assess (see Quesney, 1986; Gloor, 1992). Similarly, it is possible that the extent of amygdaloid involvement in medial temporal lobe sclerosis has been underrepresented, given the challenges in the neuropathological evaluation of amygdaloid tissue, and the surgical impediments to the en bloc excision of the amygdala. However, a recent study has reported that cell loss and gliosis in the amygdaloid complex of surgically resected temporal lobes can occur in the absence of hippocampal sclerosis (Hudson et al., 1991). Furthermore, the recent reports of Feindel and Rasmussen on paticnts that experienced partial temporal lobectomies favor an important role for the amygdala in the pathogenesis of some complex partial seizures (Feindel and Rasmussen, 1991; Rasmussen and Feindel, 1991). They performed a retrospective evaluation of 100 patients with the removal of the anterior-lateral temporal cortex, the amygdala, and the anterior hippocampus, and an evaluation of an additional 100 patients with only minimal resection of the anterior hippocampus. The incidence of complete or marked reduction in seizure frequency was the same in both series of patients. These authors concluded that the removal of the temporal pole and the amygdala yields the same benefit as a much larger excision that includes the anterior hippocampus.

Finally, the results of the experiments with lidocaine deactivation of the ventral hippocampal formation (the rodent homolog of the anterior hippocampus in human) may relate to the observation that a positive clinical outcome can be obtained with a variety of restrictive neurosurgical procedures targeted at different parts of the mesial temporal lobe. In type III status in the rat, deactivation of the ventral hippocampal formation does not eliminate all epileptiform activity, but it does prevent the recurrent development of discrete episodes of sustained ictal discharges and facial and forelimb clonus. In other terms, the convulsive manifestations are suppressed, while the subconvulsive activities remain. In a similar manner, the selective ablation of the anterior hippocampus in some patients with complex partial seizures of temporal lobe origin may interrupt pathways by which ictal activity propagates through the hippocampus into an extended network of interconnected neural structures. A similar effect might be obtained with restricted resections of the amygdaloid complex or cortical areas in the parahippocampal gyrus, with sparing of the anterior hippocampus, by blocking focal drive from the amygdala or interrupting connections to the hippocampus. Surgical procedures need not remove the epileptogenic focus per se to achieve a beneficial clinical outcome. The isolation of the discharging focus or the disconnection of the seizure network may be sufficient to attain a meaningful reduction in ictal frequency and/or severity (see also Goldring et al., 1992).

In conclusion, the primary importance of these experimental findings is the demonstration of the exceptional epileptogenic potential of two restricted parts of the amygdaloid complex, the amygdalohippocampal area and the basal nucleus, both of which are present in humans (e.g., de Olmos, 1990). These models of status epilepticus in the rat may be particularly important for the understanding of human complex partial status epilepticus (see White and Price, 1993), and seizure mechanisms that are not dependent upon the involvement of the hippocampal for- 
mation (e.g., de Lanerolle and Spencer, 1991; Gloor, 1992). Further experimental and clinical studies are necessary to fully appreciate the importance of the basal nucleus and the amygdalohippocampal area in these and other forms of seizure activity in patients with temporal lobe epilepsy.

\section{Appendix}

$\begin{array}{ll}\text { Abbreviations } \\ \text { Acc } & \text { nucleus accumbens } \\ \text { AIIA } & \text { amygdalohippocampal arca } \\ \text { AI }_{d} & \text { agranular insular cortex, dorsal division } \\ \text { AI }_{p} & \text { agranular insular cortex, posterior division } \\ \text { B } & \text { basal nucleus of the amygdala } \\ \text { BNST } & \text { bed nucleus of the stria terminalis } \\ \text { CA1 } & \text { hippocampal subfield CA 1 } \\ \text { CA3 } & \text { hippocampal subfield CA3 } \\ \text { Co } & \text { posterior cortical nucleus of the amygdala } \\ \text { C/P } & \text { caudate/putamen } \\ \text { DG } & \text { dentate gyrus } \\ \text { DLO } & \text { dorsolateral orbital cortex } \\ \text { E } & \text { dorsal endopiriform nucleus } \\ \text { L } & \text { lateral nucleus of the amygdala } \\ \text { LEA } & \text { lateral entorhinal area } \\ \text { OT } & \text { olfactory tubercle } \\ \text { PC } & \text { piriform cortex, anterior subdivision } \\ \text { PC } & \text { piriform cortex, posterior subdivision } \\ \text { PL } & \text { prelimbic cortex } \\ \text { PR } & \text { perirhinal cortex } \\ \text { SN } & \text { substantia nigra } \\ \text { SUB } & \text { subiculum } \\ \text { VLEA } & \text { ventrolateral entorhinal area } \\ \text { VP } & \text { ventral pallidum }\end{array}$

\section{References}

Adams PR, Brown DA, Constanti A (1982) M-currents and other potassium currents in bullfrog sympathetic neurones. J Physiol (Lond) 330:537-572.

Babb TL, Lieb JP, Brown WJ, Pretorius J, Crandall PH (1984a) Distribution of pyramidal cell density and hyperexcitability in the epileptic human hippocampal formation. Epilepsia 25:721-728.

Babb TL, Brown WJ, Pretorius J, Davenport C, Lieb JP, Crandall PH (1984b) Temporal lobe volumetric cell densities in temporal lobe epilepsy. Epilepsia 25:729-740.

Benardo LS, Prince DA (1982) Ionic mechanisms of cholinergic excitation in mammalian hippocampal pyramidal cells. Brain Res 249 : 333-344.

Ben-Ari Y, Zigmond RE, Shute CCD, Lewis PR (1977) Regional distribution of choline acetyltransferase and acetylcholinesterase within the amygdaloid complex and stria terminalis system. Brain Res 120: $435-445$.

Ben-Ari Y, Krnjevic K, Reinhardt W (1979) Hippocampal seizures and failure of inhibition. Can J Physiol Pharmacol 57:1462-1466.

Bruton CJ (1988) The ncuropathology of temporal lobe epilepsy. In: Institute Of psychiatry Maudsley monographs, Vol 31 (Russell G, Marley E, eds), pp 1-155. Oxford: Oxford UP.

Buterbaugh GG, Michelson HB, Keyser DO (1986) Status epilepticus facilitated by pilocarpine in amygdala-kindled rats. Exp Neurol 94: 91-102.

Cain DP, Desborough KA, McKitrick DJ (1988) Retardation of amygdala kindling by antagonism of NMD-aspartate and muscarinic cholinergic receptors: evidence for the summation of excitatory mechanisms in kindling. Exp Neurol 100:179-187.

Canteras NS, Swanson LW (1992) Connections of the posterior nucleus of the amygdala. J Comp Neurol 324:143-179.

Carlsen J, Zaborszky L, Heimer L (1985) Cholinergic projections from the basal forebrain to the basolateral amygdaloid complex: a combined retrograde fluorescent and immunohistochemical study. J Comp Neurol 234:155-167.

Chen QX, Stelzer A, Kay AR, Wong RKS (1990) GABA receptor function is regulated by phosphorylation in acutely dissociated guineapig hippocampal neurones. J Physiol (Lond) 420:207-221.

Clifford DB, Olney JW, Maniotis A, Collins RC, Zorumski CF (1987)
The functional anatomy and pathology of lithium-pilocarpine and high-dose pilocarpine seizures. Neuroscience 23:953-968.

Collins RC, Tearse RG, Lothman EW (1983) Functional anatomy of limbic seizures: focal discharges from medial entorhinal cortex in rat. Brain Res 280:25-40.

de Lanerolle NC, Spencer DD (1991) Neurotransmitter markers in human seizure foci. In: Neurotransmitters and epilepsy (Fisher RS, ed), pp 201-217. New York: Wiley-Liss.

de Lanerolle NC, Kim JH, Robbins RJ, Spencer DD (1989) Hippocampal interneuron loss and plasticity in human temporal lobe epilepsy. Brain Res 495:387-395.

de Olmos JS (1990) Amygdaloid nuclear gray complex. In: The human nervous system (Paxinos G, ed), pp 583-710. San Diego: Academic.

Feindel W, Rasmussen $T$ (1991) Temporary lobectomy with amygdalectomy and minimal hippocampal resection: review of 100 cases. Can J Neurol Sci 18:603-605.

Feindel W, Robitaille Y, Tampieri D, Goossens L, Li M, Melançon D (1991) Electroencephalography, magnetic resonance imaging and pathology in patients treated surgically for temporal lobe epilepsy. Can J Neurol Sci 18:577-579.

Gale K (1985) Mechanisms of seizure control mediated by gammaaminobutyric acid: role of the substantia nigra. Fed Proc 44:24142424.

Gale K (1988) Progression and generalization of seizure discharge: anatomical and neurochemical substrates. Epilepsia 29[Suppl 2]:S15S34.

Gale K, Browning RA (1986) Anatomical and neurochemical substrates of clonic and tonic seizures. In: Mechanisms of epileptogenesis (Dichter MA, ed), pp 1-15. New York: Plenum.

Gloor P (1987) Volume conductor principles: their application to the surface and depth electroencephalogram. In: Presurgical evaluation of epileptics (Wieser HG, Elger CE, eds), pp 59-68. Berlin: Springer.

Gloor P (1992) Role of the amygdala in temporal lobe epilepsy. In: The amygdala: neurobiological aspects of emotion, memory, and mental dysfunction (Aggleton JP, ed), pp 505-538. New York: WileyLiss.

Goddard GV, McIntyre DC, Leech CK (1969) A permanent change in brain function resulting from daily electrical stimulation. Exp Neurol 25:295-330.

Goldring S, Edwards 1, Harding GW, Bernardo KL (1992) Results of anterior temporal lobectomy that spares the amygdala in patients with complex partial seizures. J Neurosurg 77:185-193.

Handforth A, Ackermann RF (1988) Functional $\left[{ }^{14} \mathrm{C}\right] 2$-deoxyglucose mapping of progressive states of status epilepticus induced by amygdala stimulation in rat. Brain Res 460:94-102.

Hellendall RP, Godfrey DA, Ross CD, Armstrong DM, Price JL (1986) The distribution of choline acetyltransferase in the rat amygdaloid complex and adjacent cortical areas, as determined by quantitative micro-assay and immunohistochemistry. J Comp Neurol 249:486498.

Hoffman WH, Haberly LB (1989) Bursting induces persistent all-ornone EPSPs by an NMDA-dependent process in piriform cortex. $\mathbf{J}$ Neurosci 9:206-215.

Hoffman WH, Haberly LB (1991) Bursting-induced epileptiform EPSPs in slices of piriform cortex are generated by deep cells. J Neurosci 11: 2021-2031.

Houser CR, Harris AB, Vaughn JE (1986) Time course of the reduction of GABA terminals in a model of focal epilepsy: a glutamic acid decarboxylase immunocytochemical study. Brain Res 383:129-145.

Houser CR, Miyashiro JE, Swartz BE, Walsh GO, Rich JR, DelgadoEscueta AV (1990) Altered patterns of dynorphin immunoreactivity suggest mossy fiber reorganization in human hippocampal epilepsy. J Neurosci 10:267-282.

Hudson LP, Munoz DG, Girvin JP, Miller L (1991) Amygdalar sclerosis: a novel pattern in temporal lobe epilepsy. Soc Neurosci Abstr $17: 1253$

Kapur J, Iothman EW (1989) Ioss of inhibition precedes delayed spontaneous seizures in the hippocampus after tetanic electrical stimulation. J Neurophysiol 61:427-434.

Kapur J, Stringer JL, Lothman EW (1989) Evidence that repetitive seizures in the hippocampus cause a lasting reduction of GABAergic inhibition. J Neurophysiol 61:417-426.

Krellek J, Price JL (1978) A description of the amygdaloid complex in the rat and cat with observations on intra-amygdaloid axonal connections. J Comp Neurol 178:255-280. 
Krnjevic K (1983) GABA-mediated inhibitory mechanisms in relation to epileptic discharges. In: Basic mechanisms of neuronal hyperexcitability (Jasper HH, van Gelder NM, eds), pp 249-280. New York: Liss.

Lothman EW (1990) The biochemical basis and pathophysiology of status epilepticus. Neurology 4[Suppl 2]:13-23.

Lothman EW, Bertram EH, Bekenstein JW, Perlin JB (1989) Selfsustaining limbic status epilepticus induced by 'continuous' hippocampal stimulation: electrographic and behavioral characteristics. Epilepsy Res 3:107-119.

Lothman EW, Bertram EH, Stringer JL (1991) Functional anatomy of hippocampal seizures. Prog Brain Res 37:1-82.

Ludvig N, Moshé SL (1988) Deep prepiriform cortex lesion and development of amygdala kindling. Epilepsia 29:401-403.

Martin JH (1991) Autoradiographic estimation of the extent of reversible inactivation produced by microinjection of lidocaine and muscimol in the rat. Neurosci Lett 127:160-164.

McDonald AJ (1982) Neurons of the lateral and basolateral amygdaloid nuclei: a Golgi study in the rat. J Comp Neurol 212:293-312.

McDonough JH, McLeod CG, Nipwoda T (1987) Direct microinjection of soman or VX into the amygdala produces repetitive limbic convulsions and neuropathology. Brain Res 435:123-137.

McIntyre DC, Kelley ME (1993) Are differences in dorsal hippocampal kindling related to amygdala-piriform area excitability? Epilepsy Res 14:49-61.

McIntyre DC, Plant JR (1989) Pyriform cortex involvement in kindling. Neurosci Biobehav Rev 13:277-280.

McIntyre DC, Nathanson D, Edson N (1982) A new model of partial status epilepticus based on kindling. Brain Res 250:53-63.

McIntyre DC, Don JC, Edson N (1991) Distribution of $\left[{ }^{14} \mathrm{C}\right] 2$-deoxyglucose after various forms and durations of status epilepticus induced by stimulation of a kindled amygdala focus in rats. Epilepsy Res 10: 119-133.

McIntyre DC, Dufresne C, Kelley ME, Mohapel P (1992) Kindling characteristics and susceptibility to status epilepticus of various temporal lobe structures. Soc Neurosci Abstr 18:906.

Mesulam M-M (1978) Tetramethyl-benzidine for horseradish peroxidase neurohistochemistry: a non-carcinogenic blue reaction product with superior sensitivity for visualizing neural afferents and efferents. J Histochem Cytochem 26:106-117.

Morimoto K, Dragunow M, Goddard GV (1986) Deep prepyriform cortex kindling and its relation to amygdala kindling in the rat. Exp Neurol 94:637-648.

Olney JW, de Gubareff T, Labruyere J (1983) Seizure-related brain damage induced by cholinergic agents. Nature 301:520-522.

Olney JW, Collins RC, Sloviter RS (1986) Excitotoxic mechanisms of epileptic brain damage. Adv Neurol 44:857-877.

Ottersen OP (1982) Connections of the amygdala of the rat. IV. Corticoamygdaloid and intraamygdaloid connections as studied with axonal transport of horseradish peroxidase. J Comp Neurol 205:30-48.

Paxinos G, Watson C (1986) The rat brain in stereotaxic coordinates, 2d ed. Orlando: Academic.

Piredda S, Gale K (1985) A crucial epileptogenic site in the deep prepiriform cortex. Nature 317:623-625.

Quesney LF (1986) Clinical and EEG features of complex partial seizures of temporal lobe origin. Epilepsia 27[Suppl 2]:S27-S45.

Rainnie DG, Asprodini EK, Shinnick-Gallagher P (199la) Excitatory transmission in the basolateral amygdala. J Neurophysiol 66:986998.

Rainnie DG, Asprodini EK, Shinnick-Gallagher P (1991b) Inhibitory transmission in the basolateral amygdala. J Neurophysiol 66:9991009

Rasmussen T, Feindel W (1991) Temporal lobectomy: review of 100 cases with major hippocampectomy. Can J Neurol Sci 18:601-602.

Roberts E (1984) G $\mathrm{B} \Lambda$-related phenomena, models of nervous system function, and seizures. Ann Neurol [Suppl] 16:S77-S89.

Sloviter RS (1991a) Feedforward and feedback inhibition of hippocampal principal cell activity evoked by perforant path stimulation: GABA-mediated mechanisms that regulate excitability in vivo. Hippocampus $1: 31-40$.
Sloviter RS (1991b) Permanently altered hippocampal structure, excitability, and inhibition after experimental status epilepticus in the rat: the "dormant basket cell" hypothesis and its possible relevance to temporal lobe epilepsy. Hippocampus 1:41-66.

Stringer JL, Lothman EW (1989) Maximal dentate activation: characteristics and alterations after repeated seizures. J Neurophysiol 62: 136-143.

Stringer JL, Lothman EW (1990) Pharmacological evidence indicating a role of $\mathrm{G} \Lambda \mathrm{B} \Lambda$ ergic systems in termination of limbic scizurcs. Epilepsy Res 7:197-204.

Stringer JL, Lothman EW (1992) Bilateral maximal dentate activation is critical for the appearance of an afterdischarge in the dentate gyrus. Neuroscience 46:309-314.

Stringer JL, Williamson JM, Lothman EW (1989) Induction of paroxysmal discharges in the dentate gyrus: frequency dependence and relationship to afterdischarge production. J Neurophysiol 62:126135.

Stringer JL, Williamson JM, Lothman EW (1991) Maximal dentate activation is produced by amygdala stimulation in unanesthetized rats. Brain Res 542:336-342.

Stripling JS, Patneau DK (1990) Seizure mechanisms in the piriform cortex. In: Kindling 4 (Wada JA, ed), pp 45-57. New York: Plenum.

Sutula T, Cascino G, Cavazos J, Parada I, Ramirez L (1989) Mossy fiber synaptic reorganization in the epileptic human temporal lobe. Ann Neurol 26:321-330.

Tremblay E, Ottersen OP, Rovira C, Ben-Ari Y (1983) Intra-amygdaloid injections of kainic acid: regional metabolic changes and their relation to the pathological alterations. Neuroscience 8:299-315.

Tseng G-F, Haberly LB (1989a) Deep neurons in the piriform cortex I. Morphology and synaptically evoked responses including a unique high-amplitude paired shock facilitation. J Neurophysiol 62:369-385.

Tseng G-F, Haberly LB (1989b) Deep neurons in the piriform cortex II. Membrane properties that underlie unusual synaptic responses. J Neurophysiol 62:386-400.

Turner BH, Zimmer J (1984) The architecture and some of the interconnections of the rat's amygdala and lateral periallocortex. J Comp Neurol 227:540-557.

Turski L, Ikonomidou C, Turski WA, Bortolotto ZA, Cavalheiro EA (1989) Review: cholinergic mechanisms and epileptogenesis. The seizures induced by pilocarpine: a novel experimental model of intractable epilepsy. Synapse 3:154-171.

Turski WA, Czuczwar SJ, Kleinrok Z, Turski L (1983) Cholinomimetics produce seizures and brain damage in rats. Experientia 39 . 1408-1411.

VanLandingham KE, Lothman EW (199 la) Self-sustaining limbic status epilepticus. I. Acute and chronic cerebral metabolic studies: limbic hypermetabolism and neocortical hypometabolism. Neurology 41: 1942-1949.

VanLandingham KE, Lothman EW (1991b) Self-sustaining limbic status epilepticus. II. Role of hippocampal commissures in metabolic responses. Neurology 41:1950-1957.

Wada JA, Sato M (1974) Generalized convulsive seizures induced by daily electrical stimulation of the amygdala in cats. Neurology 24 : 565-574.

Wahnschaffe U, Löscher W (1990) Lesions of the deep prepiriform cortex ('area tempestas') in rats do not affect the convulsant action of systemically administered bicuculline. Neurosci Lett 108:161-166.

White LE (1992) The functional anatomy of limbic status epilepticus. Doctoral thesis, Washington University, St. Louis, MO.

White LE, Price JL (1993) The functional anatomy of limbic status epilepticus in the rat. I. Patterns of ${ }^{14} \mathrm{C}$-2-deoxyglucose uptake and Fos immunocytochemistry. J Neurosci 13:4787-4809.

White LE, Carnes KM, Price JL (1988) The effects of low doses of ketamine on patterns of 2-deoxyglucose uptake with amygdaloid stimulation. Soc Neurosci Abstr 14:1150.

Woolf NJ, Butcher LL (1982) Cholinergic projections to the basolateral amygdala: a combined Evans blue and acetylcholinesterase analysis. Brain Res Bull 8:751-763. 